\title{
Influx mechanisms in the embryonic and adult rat choroid plexus: a transcriptome study
}

\author{
Norman R. Saunders ${ }^{1 *}$, Katarzyna M. Dziegielewska ${ }^{1}$, Kjeld Møllgård $^{2}$, Mark D. Habgood ${ }^{1}$, \\ Matthew J. Wakefield ${ }^{3}$, Helen Lindsay ${ }^{4}$, Nathalie Stratzielle ${ }^{5}$, Jean-Francois Ghersi-Egea ${ }^{5}$ \\ and Shane A. Liddelow ${ }^{1,6}$

\begin{abstract}
${ }^{1}$ Department of Pharmacology and Therapeutics, University of Melbourne, Parkville, VIC, Australia, ${ }^{2}$ Department of Cellular and Molecular Medicine, University of Copenhagen, Copenhagen, Denmark, ${ }^{3}$ Walter and Eliza Hall Institute of Medical Research, Parkville, VIC, Australia, ${ }^{4}$ Institute of Molecular Life Sciences, University of Zurich, Zurich, Switzerland, ${ }^{5}$ Lyon Neuroscience Research Center, INSERM U1028, Centre National de la Recherche Scientifique UMR5292, Université Lyon 1 ,
\end{abstract} \\ Lyon, France, ${ }^{6}$ Department of Neurobiology, Stanford University, Stanford, CA, USA
}

\section{OPEN ACCESS}

Edited by:

Joana A. Palha

University of Minho, Portugal

Reviewed by:

Fernanda Marques,

University of Minho, Portugal Hanspeter Herzel,

Humboldt University, Germany

*Correspondence:

Norman R. Saunders, Department of Pharmacology and Therapeutics, University of Melbourne,

Triradiate Building, Grattan Street,

Parkville, VIC 3010, Australia

n.saunders@unimelb.edu.au

Specialty section:

This article was submitted to

Neurogenomics,

a section of the journal

Frontiers in Neuroscience

Received: 24 December 2014 Accepted: 24 March 2015

Published: 28 April 2015

Citation:

Saunders NR, Dziegielewska KM, Møllgård K, Habgood MD, Wakefield $M J$, Lindsay $H$, Stratzielle $N$,

Ghersi-Egea J-F and Liddelow SA (2015) Influx mechanisms in the embryonic and adult rat choroid plexus: a transcriptome study. Front. Neurosci. 9:123. doi: 10.3389/fnins.2015.00123
The transcriptome of embryonic and adult rat lateral ventricular choroid plexus, using a combination of RNA-Sequencing and microarray data, was analyzed by functional groups of influx transporters, particularly solute carrier (SLC) transporters. RNA-Seq was performed at embryonic day (E) 15 and adult with additional data obtained at intermediate ages from microarray analysis. The largest represented functional group in the embryo was amino acid transporters (twelve) with expression levels 2-98 times greater than in the adult. In contrast, in the adult only six amino acid transporters were up-regulated compared to the embryo and at more modest enrichment levels (<5-fold enrichment above E15). In E15 plexus five glucose transporters, in particular Glut-1, and only one monocarboxylate transporter were enriched compared to the adult, whereas only two glucose transporters but six monocarboxylate transporters in the adult plexus were expressed at higher levels than in embryos. These results are compared with earlier published physiological studies of amino acid and monocarboxylate transport in developing rodents. This comparison shows correlation of high expression of some transporters in the developing brain with higher amino acid transport activity reported previously. Data for divalent metal transporters are also considered. Immunohistochemistry of several transporters (e.g., S/c16a10, a thyroid hormone transporter) gene products was carried out to confirm translational activity and to define cellular distribution of the proteins. Overall the results show that there is substantial expression of numerous influx transporters in the embryonic choroid plexus, many at higher levels than in the adult. This, together with immunohistochemical evidence and data from published physiological transport studies suggests that the choroid plexus in embryonic brain plays a major role in supplying the developing brain with essential nutrients.

Keywords: choroid plexus, brain development, amino acid transfer, protein transfer, brain barriers, cerebrospinal fluid

Abbreviations: E, embryonic day; CSF, cerebrospinal fluid. 


\section{Introduction}

Influx transporters, active across interfaces between the blood and the brain, are essential components of the mechanisms that contribute to the composition and stability of the internal environment of the brain, critical for normal brain function. The main interfaces between these two compartments are the blood-brain barrier across cerebral blood vessels and the bloodcerebrospinal (CSF) barrier across the choroid plexuses within the cerebral ventricles (Saunders et al., 2012). The transport mechanisms in these interfaces have been well studied in the adult brain (Davson and Segal, 1996; Brown et al., 2004; Damkier et al., 2007, 2013; Abbott et al., 2010; Abbott and Friedman, 2012) but relatively little is known about them during gestation, although they are clearly important for normal brain development and maturation. In addition, much of the research focus has been on the blood-brain barrier itself rather than on the transport properties of the choroid plexuses. Nevertheless, in spite of this neglect, it seems that in the early developing brain the choroid plexuses are probably a much more important portal of entry into the brain than are the cerebral blood vessels (Johansson et al., 2008). This is because the choroid plexuses develop to being a substantial and functional tissue at a stage when the brain is still poorly vascularised (Saunders et al., 2012, 2013). By far the largest group of influx transporters is the solute carrier gene series (SLCs), which currently comprises 52 families of 395 transporter genes (Hediger, 2013 and http://www.bioparadigms. org/slc/intro.htm). These are particularly important for ion exchange and amino acid and glucose delivery to the brain. Until recently, very little was known about their expression and function in the choroid plexuses of the developing brain. This paper is the third in a series of combined RNA-Sequencing and microarray analysis of transcriptome expression in developing and adult choroid plexus, with a focus on the plexuses in the lateral ventricles (Kratzer et al., 2013; Liddelow et al., 2013). Here we give a comprehensive analysis of the expression of solute carriers and other influx transporters in developing and adult choroid plexus, with an emphasis on nutrient transporters such as for glucose, amino acids and monocarboxylates and compare these data with available published physiological data on their transport activity in vivo. We also include results of immunohistochemical staining of selected SLCs, which confirm that their genes are translating to protein both in the embryo and in the adult. The ion transporters thought to be important for CSF secretion and its homeostasis, as well as brain interstitial fluid have been dealt with in a previous paper (Liddelow et al., 2013) together with the ABC/SLC transporters specifically involved in neuroprotective CSF-to-blood efflux mechanisms (Kratzer et al., 2013). Comparative data are also available from a microarray study of mouse choroid plexus (Liddelow et al., 2012) and an RNA-Seq study of non human primate choroid plexus (Ek et al., 2015).

\section{Materials and Methods}

The animal tissue obtained for this study came from two earlier published studies and most methods were as previously described (Kratzer et al., 2013; Liddelow et al., 2013).

\section{Ethics Statement}

Animal experiments in Melbourne were conducted in accordance with Australian code of practice for the care and use of animals for scientific purposes 7th Edition, published by the National Health and Medical Research Council. All animal research protocols were reviewed and approved by the University of Melbourne Faculty of Medicine, Dentistry and Health Sciences Animal Ethics Committee and registered under ID. Number 1011703. For experiments conducted in Lyon animal care and procedures were in accordance with the guidelines approved by the French ethical committee (decree 87-848), by the European Community (directive 86-609-EEC).

\section{Animal Husbandry}

In Melbourne, timed-pregnant (embryonic day 15, E15) and non-pregnant adult (6 week, 200-300g weight range) SpragueDawley rats were used. These ages were chosen as they have been previously shown to be appropriate for studies of the developing lateral ventricular choroid plexus in rodents (Johansson et al., 2006; Liddelow et al., 2012). Animals were supplied by the Biological Research Facility at the University of Melbourne (Victoria, Australia). For next generation RNA-Sequencing, lateral ventricular choroid plexuses from E15 $(n=30)$ and female adult $(n=30)$ rats were used. For immunohistochemistry E15 $(n=3)$ and female adult $(n=3)$ lateral ventricular choroid plexuses were dissected out and processed as described below. For microarray experiments Sprague-Dawley rats (adult males, pregnant time-dated females, or females with their litters) were obtained from Janvier (Le Genest Saint Isle, France). All animals were kept under similar conditions in standard cages, with free access to food and tap water under a controlled environment (12 h day/light cycles).

\section{Collection of Lateral Ventricular Choroid Plexus}

The procedure for collection of choroid plexus tissues has previously been described (Liddelow et al., 2012; Kratzer et al., 2013). Briefly, animals were killed by an overdose of inhaled isoflurane (Veterinary Companies of Australia) and brains dissected out under ice-cold RNase-free phosphate buffered saline (PBS, $\mathrm{pH}$ 7.3). Both left and right lateral ventricular choroid plexuses were carefully dissected out and placed in fresh ice-cold RNase-free PBS. All steps were performed under RNasefree conditions. The collected tissues were snap-frozen in liquid nitrogen and kept at $-80^{\circ} \mathrm{C}$ until used.

For Illumina RNA-Sequencing, lateral ventricular choroid plexuses from $\mathrm{E} 15(n=30)$ and adult $(n=30)$ rats were used (three pooled samples of ten plexuses at each age). Total RNA was extracted using the RNeasy Mini Kit, Qiashredder columns and gDNA removal columns (Qiagen, Valencia, CA, USA) according to standard supplier protocols. All RNA samples were quantified using a NanoDrop ND-1000 UVVIS spectrophotometer (Thermo Scientific, Wilmington, DE, USA) and quality checked with the Agilent 2100 Bioanalyzer (Agilent Technologies, Palo Alto, CA, USA). Plexuses were pooled ( $n=10$ animals) and centrifuged at $1000 \mathrm{rpm}$ for $30 \mathrm{~s}$, excess PBS removed, snap frozen in liquid nitrogen and stored at $-80^{\circ} \mathrm{C}$. For Affymetrix microarrays, choroid plexuses were pooled from 3 to 5 animals. Total RNA was isolated from two 
pools of choroid plexuses sampled from E19, P2, or adult rats using the RNeasy ${ }^{\circledR}$ Micro Kit (Qiagen, Valencia, CA, USA), and DNase-treated according to the manufacturer's protocol.

The choroid plexus consists of epithelium as well as blood vessels, neural innervation and mesenchymal stroma. However, the epithelium is the predominant cell type, suggested to represent up to $90 \%$ of the plexus tissue (Keep and Jones, 1990; Liddelow et al., 2012). In this study lateral ventricular choroid plexus was taken in toto.

\section{Illumina Next Generation RNA Sequencing}

RNA Sequencing was performed at the Australian Genome Research Facility (Melbourne, VIC, Australia). A cDNA library was prepared from $10 \mu \mathrm{g}$ of total RNA using the mRNASeq Sample Preparation Kit (Illumina, San Diego, CA, USA) according to standard manufacturer protocol. Quality of the library was verified using a DNA 1000 chip using the Agilent 2100 Bioanalyzer (Agilent). The library was subjected to $100 \mathrm{bp}$ single end read cycles of sequencing on an Illumina HiSeq 2000 sequencer as per manufacturer protocol. Cluster generation was performed on a c-Bot (Illumina) with a single read cluster generation kit.

\section{Data Analysis}

Short reads were trimmed to remove ambiguous bases from the start and segments with low quality scores from the end, as indicated by the ascii character " $\mathrm{B}$ " in Illumina 1.5 phred score encoding. Trimmed reads were mapped with Bowtie version 0.12.7 (Langmead et al., 2009) to the Ensembl (Hubbard et al., 2009) rat genome, release 61. Reads that did not map uniquely were discarded. The number of reads mapped to nuclear genes was determined with HTSeq (Anders, 2010) version $0.4 .7 \mathrm{p} 4$, using the default "union" counting option. Differential expression between the adult and embryonic samples was detected using an exact test in the Bioconductor (Gentleman et al., 2004) edgeR package, version 2.4.0 (Robinson et al., 2010), with common dispersion used to estimate variance between samples. Genes considered significantly differentially expressed were those with a $p$-value of less than 0.05 after BenjaminiHochberg false discovery rate correction. All fold changes during development were calculated from these normalized data. However, where appropriate we have also included raw counts for each transcript. As noted in the legends to relevant tables (Tables 4-6) ratios for individual genes calculated from raw counts may not correspond to the fold changes (as shown in the tables) calculated from normalized data. We have included both the normalized fold changes and raw cell counts to enable the reader to see both relative expression changes throughout development, as well as the absolute abundance of each transcript at an individual age. A combination of gene ontology annotation and manual curation was used to select genes encoding proteins with integral transporter function. Gene ontology descriptions for rat were downloaded from Biomart (Hubbard et al., 2009), and genes with "transport" mentioned in their gene ontology description were selected. Genes of interest were then extracted from this list. For initial analysis genes with $>100$ sequence reads and age-related fold changes $(\mathrm{FC})>2.0\left(\log _{2} \mathrm{FC}>1.0\right)$ were collated and are summarized in Tables 4-6, and Supplementary
Tables S1-S3; this level of gene expression was taken as likely to be functionally significant. For identification of the presence of a particular gene a lower cut-off of 10 sequence reads was used; these are also included in Tables 4-6. Illumina RNA sequencing data have been deposited with the Gene Expression Omnibus (http://www.ncbi.nlm.nih.gov/geo/) under accession code GSE44072.

\section{Microarray}

As previously described (Kratzer et al., 2013) microarray analysis was performed using a high-density oligonucleotide array (GeneChip Rat Genome 2302.0 array, Affymetrix, Santa Clara, CA, USA). Total RNA (100 ng) was amplified and biotin-labeled using GeneChip ${ }^{\circledR} 3^{\prime}$ IVT Express target labeling and control reagents according to Affymetrix protocol (http://www.affymetrix.com). Before amplification, all samples were spiked with synthetic mRNAs at different concentrations, which were used as positive controls to ascertain the quality of the process. Biotinylated antisense cRNA for microarray hybridization was prepared. After final purification using magnetic beads, cRNAs were quantified using a NanoDrop and quality checked with Agilent 2100 Bioanalyzer. Hybridization was performed according to the Affymetrix protocol. Briefly, $10 \mu \mathrm{g}$ of labeled cRNA was fragmented and denaturated in hybridization buffer, then hybridized on the chip for $16 \mathrm{~h}$ at $45^{\circ} \mathrm{C}$ with constant mixing by rotation at $60 \mathrm{rpm}$ in a Genechip hybridization oven 640 (Affymetrix). After hybridization, arrays were washed and stained with streptavidin-phycoerythrin (GeneChip ${ }^{\circledR}$ Hybridization Wash and Stain Kit) in a fluidic station 450 (Affymetrix) according to the manufacturer's instruction. The arrays were read with a confocal laser (Genechip scanner 3000, Affymetrix). CEL files summarizing the probe cell intensity data were generated using the Affymetrix GeneChip Command Console (AGCC) software 3.0. Data were normalized with Affymetrix Expression Console software using MAS5 statistical algorithm. Data have been deposited into the Gene Expression Omnibus repository (http://www.ncbi.nlm.nih.gov/ geo) under accession number GSE44056.

\section{Immunohistochemistry}

Sagittal sections through E15 and adult rat brain including lateral choroid plexus were selected from the collection of rat tissue at the Faculty of Health and Medical Sciences, University of Copenhagen and used for immunohistochemical detection of SLC16a10, Slc38a5 (SNAT5), Slc4a1, Slc1la1 (NRAMP), Slc39a4 (ZIP4), and Slc1a3 (EAAT1). Sections were deparaffinised in xylene, rehydrated through graded alcohols followed by treatments in $0.5 \%$ hydrogen peroxide in methanol for $15 \mathrm{~min}$ and rinsing in TRIS buffered saline (TBS) as described previously (Liddelow et al., 2012). Following removal of nonspecific binding by incubation for $30 \mathrm{~min}$ with blocking buffer (ChemMate antibody diluent S2022, DakoCytomation, Glostrup, Denmark) at room temperature sections were incubated in primary antibodies as listed in Table $\mathbf{1}$.

After overnight incubation sections were washed in TBS and incubated for $30 \mathrm{~min}$ in EnVisionTM+ System/HRP (DAKO), K5007, for rabbit antibodies and RPN1025 from GE Healthcare for donkey anti-goat antibodies and then Vector: Vectastain 
TABLE 1 | List of primary antibodies used for immunohistochemistry.

\begin{tabular}{llcclc}
\hline Primary antibody & Host IgG & Dilution & Retrieval & Producer & Code number \\
\hline Slc16a10 (MCT10) & Rabbit & $1: 20$ & M6 & Abcam & Ab121519 \\
Slc38a5 (SNAT5) & Goat & $1: 150$ & - & Santa Cruz & Sc-50682 \\
Slc4a1 (AE1) & Rabbit & $1: 100$ & - & Proteintech & $18566-1-A P$ \\
Slc11a1 (NRAMP) & Rabbit & $1: 70$ & - & Santa Cruz & Sc-20113 \\
Slc1a3 (EAAT1) & Rabbit & $1: 600$ & - & Abcam & Ab416 \\
Slc5a5 (NIS) & Rabbit & $1: 200$ & - & Proteintech & $24324-1-A P$ \\
SLC 39a4 (ZIP4) & Rabbit & $1: 200$ & - & Proteintech & $20625-1-A P$ \\
\hline
\end{tabular}

RTU elite ABC reagent PK 7100. This was followed by 6 min incubation with DAB-chromogen solution (DAKO) and counterstaining with Mayer's haematoxylin, dehydrated and mounted with DPX. Control sections contained no primary antibodies and were always blank.

\section{Photography and Image Preparation}

Digitized images were obtained using an Olympus DP70 camera housing (Olympus, Tokyo, Japan) attached to an Olympus BX50 light microscope (Olympus). A10 $\times$ eyepiece and $40 \times$ objective lens were used. Raw image files were process in Adobe Photoshop CS5 ${ }^{\circledR}$ (Adobe ${ }^{\circledR}$ Systems, San Jose, CA, USA). The brightness and curve functions were used to obtain images with background close to white. There was no other manipulation of images.

\section{Results}

\section{Solute Carriers (SLCs) Identified by RNA-Sequencing and Microarray}

Examination of the whole transcriptome data set from RNASequencing showed 48 families of the 52 known SLC families (Hediger, 2013) and 64\% of transcripts in these families were identifiable at functionally significant levels of expression (>100 transcript reads, Figure 1, Supplementary Table S1). The distribution of genes at the two ages that showed increased, decreased or unchanged expression is illustrated in Figure 2. For each SLC family the distribution of gene expression in embryonic and adult choroid plexus is shown in Figure 3.

The Slc genes that were expressed at a higher level ( $>2$ fold) in the embryonic choroid plexus than in the adult are listed in Table 2; microarray data from E19 and P2 are also shown. The Slc genes that were expressed at a higher level ( $>2$ fold) in the adult plexus are shown in Table 3; data comparing adult with E19 and P2, from microarray, are also shown. The main focus of this report is the Slc transporter genes involved in nutrient transport into CSF, particularly amino acids, monocarboxylates and glucose.

In the present study the numerous members of the SLC families of transport proteins that were present in the lateral ventricular choroid plexus at E15 and in the adult had strikingly different patterns of gene expression at these two ages: of 250 total genes identified by RNA sequencing (Supplementary Table S2), 81 were expressed at higher levels at E15 (Supplementary Table S2 and Table 2). Developing-to-adult fold change differences between E19 and P2 were modest, apart from Slc7a11, Slc7a1, and Slc6a15, suggesting that birth is not a key milestone for developmental changes in the choroidal Slc transcriptome. A number of genes such as Slc4a1, Slc2a3, Slc11a1 had strikingly higher E15/Adult fold change than E19-P2/Adult fold changes. This suggests very specific choroidal function for brain development at the early stages of gestation. 107 genes were up-regulated in the adult (Supplementary Table S3 and Table 3). For these genes the array analysis shows that the E19/Adult and P2/Adult fold changes were modest and lower than E15/Adult fold changes for most of these genes, indicating that the choroid plexus starts to acquire its "adult" phenotype early in development, i.e., at late prenatal stages in the rat. Finally, 62 genes showed no difference in expression level between the ages (Supplementary Table S3), indicating the early maturity and life-long duration of different choroidal functions, in addition to early development-specific functions assumed from the E15 specific genes identified. Many fewer $S l c$ transporter genes have been identified at the blood-brain barrier (Daneman et al., 2010supplementary material) of about 56 transcripts, which is around a quarter of that identified in this choroid plexus study. This finding supports the previously suggested proposition that in the developing brain the choroid plexus is the main route of entry for amino acid and ion transport and other molecules essential for brain development (Johansson et al., 2008).

\section{Glucose and Monocarboxylate Transporters}

Table 4 lists the glucose and monocarboxylate transporters differentially regulated in the embryo and in the adult with a fold change (FC) of two or more. Slc5a10 (sodium/glucose co-transporter) was expressed only in the embryonic plexus, but at a low copy number. Gene array shows that it was still expressed at E19, but disappeared after birth. The number of glucose transporters expressed at a higher level in the embryo was strikingly more than those higher in the adult (five compared to two, note that Klf15 is a regulator of GLUT4, not a transporter itself, Gray et al., 2002). The converse was the case for monocarboxylate transporters; there was only one in the embryo, but 6 in the adult.

Slc2a3 (GLUT3) was only detected in the embryo using RNASeq, but in microarray data was expressed at similar levels in the adult (ratio of $0.7-0.8$ ). However, the transcript numbers in RNA-Seq were very low, so this result is of dubious functional significance. Three other glucose transporters (Slc2a4, Slc2a5, Slc45a1) had transcript numbers $<100$ at both ages and were not detected in microarray, so these genes are unlikely to be contributing to glucose transport via the choroid plexuses. More relevant is GLUT1 (Slc2a1) which is well expressed in embryonic and E19 fetal choroid plexus relative to P2 or adult. This transporter is crucial for glucose delivery to the brain. Its expression in the developing brain choroid plexus argues for a specific role of the plexus in nutrient transport at these ages. Amongst monocarboxylate transporters the same single one (Slc10a16) was increased in the developing choroid plexus in both RNA-Seq and microarray results. The most highly expressed of all the monocarboxylate transporters (in terms of transcript numbers) was Slc16a2, at a slightly higher (2.1 fold) level in 


\section{SLC Transporters Present in Rat Lateral Ventricular Choroid Plexus}

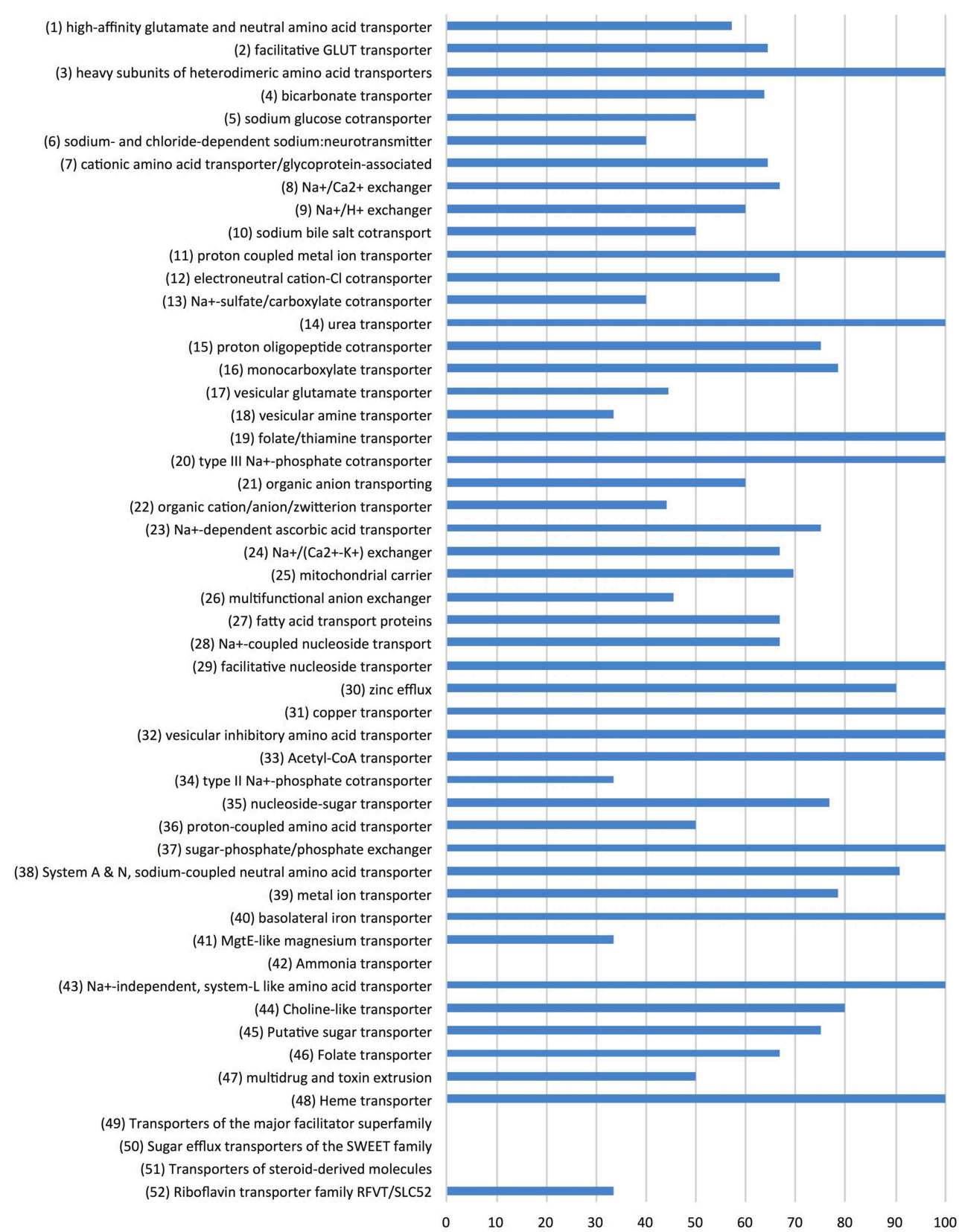

FIGURE 1 | SIC transporter genes identified in rat lateral ventricular choroid plexus. Expression of SLC family class transcripts in the rat lateral ventricular choroid plexus regardless of age, as determined by RNA sequencing. The 52 known functional groups of SLC transporters (Hediger, 2013) are shown on the left. Data are expressed as percentage total of each family of transporters (transcript number > 10)-for example, $100 \%$ of proton-coupled metal ion transporters (SLC11 family) are present in the rat lateral ventricular choroid plexus, whereas no steroid-derived molecule transporters (SLC51 family) were detected. the adult than in the embryo; this transporter was not detected in microarray, possibly because the probe was not a good match. Slc16a8 was expressed at a high level in adult plexus, but expression was $<100$ transcript counts in the embryo in the RNA-Seq analysis and was also not detected in microarray. Three other monocarboxylate transporters were expressed at high level in adult plexus in both microarray and RNA-Seq (Tables 3, 4).

\section{Amino Acid Transporters}

There were twice as many genes coding for amino acid transporters in the embryonic choroid plexus expressed at a 

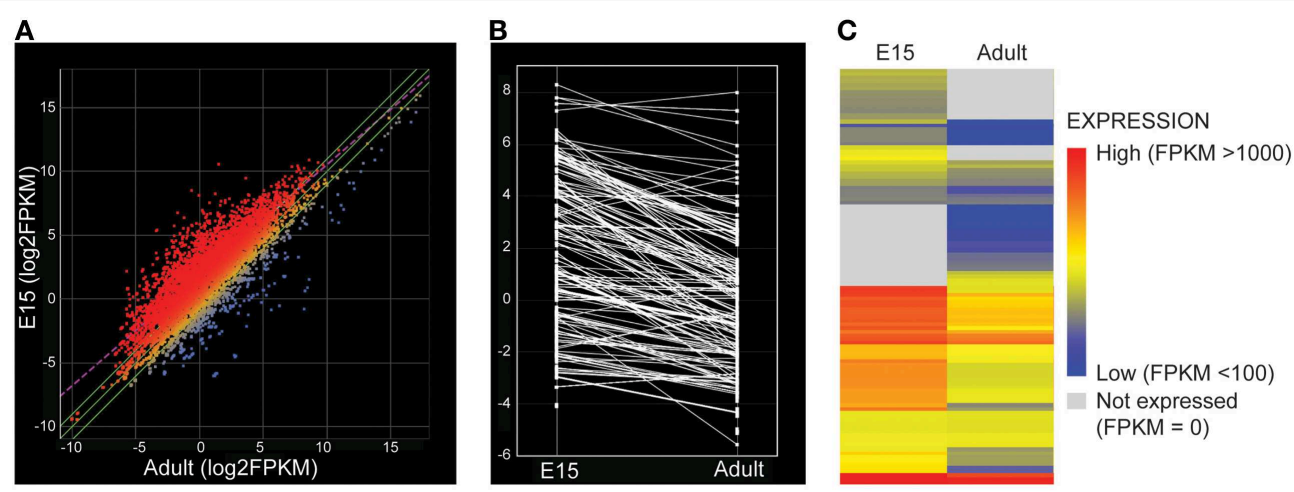

FIGURE 2 | (A) Scatter plot comparing log2(FPKM), i.e., fragment count per kilobase of exonic length per million reads mapped, for all transcripts detected by RNA sequencing of the rat lateral ventricular choroid plexus, averaged across replicates from embryonic day 15 (E15) and adult. Red points show transcripts with higher expression at E15 (greater than 2-fold) while blue points are those with higher expression in the adult. FPKM was estimated using a standard ArrayStar pipeline (http://www.dnastar.com/t-help-arraystar.aspx). There is a greater number of transcripts enriched in the embryo. (B) Parallel coordinate plot of change in average expression (log2(FPKM)) of SLC transporters in E15 and Adult lateral ventricular choroid plexus. Lines connect the same transcript present at both ages. (C) Heat map of average expression $(\log 2(\mathrm{FPKM}))$ for SLC transporters. Red depicts high expression values, blue low expression. Gray depicts transcripts that were not detected at one age. The expression level of SLC transporters was much higher at E15-as shown by more red expression data. higher level than in the adult (12 compared to 6, Table 5). The level of expression of these transporters in the embryo was also generally higher; thus in the embryo nine of the transporters were expressed at $>5$ fold compared to adult, whereas in the adult only one transporter gene was expressed $>5$ fold compared to the embryo. The microarray results were generally consistent with those from RNA-Seq (Tables 2, 4, 5). For both methods the expression levels of Slc7a11, Slc7a1, Slc6a6, and Slc6a15 were notably high in the embryonic plexus. For two genes (Slc3a1, Slc7a10) the expression levels were higher in the adult with RNA-Seq, but lower with microarray (Tables 3, 5).

\section{Divalent Metal Transporters}

It has been known for many years that zinc is important for normal brain development and for function in the adult (Sandstead, 1985; Marger et al., 2014; Tyszka-Czochara et al., 2014). In the present study there were 4 zinc transporter genes that were expressed at a higher level in embryonic choroid plexus than in the adult in the fold range of 2.5-44 (Table 6). In the adult there were more up-regulated zinc transporter genes (6), but their expression level was generally much lower (2.7-12 fold). Both of the major zinc transporter families (Slc30, ZnT, and Slc39, ZIP) are represented in our dataset. The members of the two families function in opposite directions, thus maintaining cellular zinc homeostasis. ZnT proteins of Slc30 genes efflux zinc whereas ZIP proteins function to increase zinc uptake when cellular zinc is depleted (Marger et al., 2014; Tepaamorndech et al., 2014). Ten Slc30 genes were identified in the present study (two higher in the embryo, Slc30a2, 44 FC; Slc30a10, 35 FC and four in the adult, Slc30a3-6, with only modest 2.7-4.5 FC). Ten Slc39 genes were identified; Slc39a8 was 37 FC higher in embryo. Three other members, Slc39a1, Slc39a12, and Slc39a13 (FC 12, 12 and 3.9 respectively), were higher in adult (Table 6).
The transferrin gene, $T f$, was expressed in terms of transcript numbers at a high level in both the embryo and adult (Table 6), but much higher in the latter (183 fold), with a continuous pre-and post natal increase from embryo to adult stages. The transferrin receptor was expressed at a higher level in embryonic choroid plexus (3.1 fold) with intermediate expression levels at the perinatal stage of development. As indicated in Table 6 several other iron carriers were expressed at a higher level in the embryo than in the adult: sideroflexin1, Sfxn1 (14 fold), ferritin light chain 1-like (LOC100360087), 3.6 fold), and this difference in expression was maintained perinatally.

Slc11a1 was expressed at much higher levels in the embryonic choroid plexus than in the adult ( 8.9 fold), and at still higher level at birth, while Slc11a2 (DMT1) was found expressed at a similar level at all ages examined by both RNA-Seq and microarray approaches (Table 6). Several members of these SLC families of divalent metal transporters have been implicated in iron and manganese transport. Their expression in developing choroid plexus correlates with the higher uptake of manganese by postnatal choroid plexus cells in vitro as shown by Schmitt et al. (2011), and is discussed further below.

\section{Immunohistochemistry}

Immunohistochemical investigations of the distribution of some efflux transporter proteins selected from the gene expression data included five enriched in the fetus: SLC 16a10 (TAT1), SLC 38a5 (SNAT5), SLC 4a1 (AE1), SLC 11a1 (NRAMP), SLC 1a3 (EAAT1), one enriched in the adult: SLC 5a5 (NIS) and one expressed at a low level in both fetal and adult choroid plexus: SLC 39a4 (ZIP4).

The seven tested antibodies resulted in 3 different patterns of immunoreactivity in E15 plexus epithelial cells ("differential immunoreactivity, regional distribution-type," 


\section{SLC Transporters Present in Rat Lateral Ventricular Choroid Plexus}

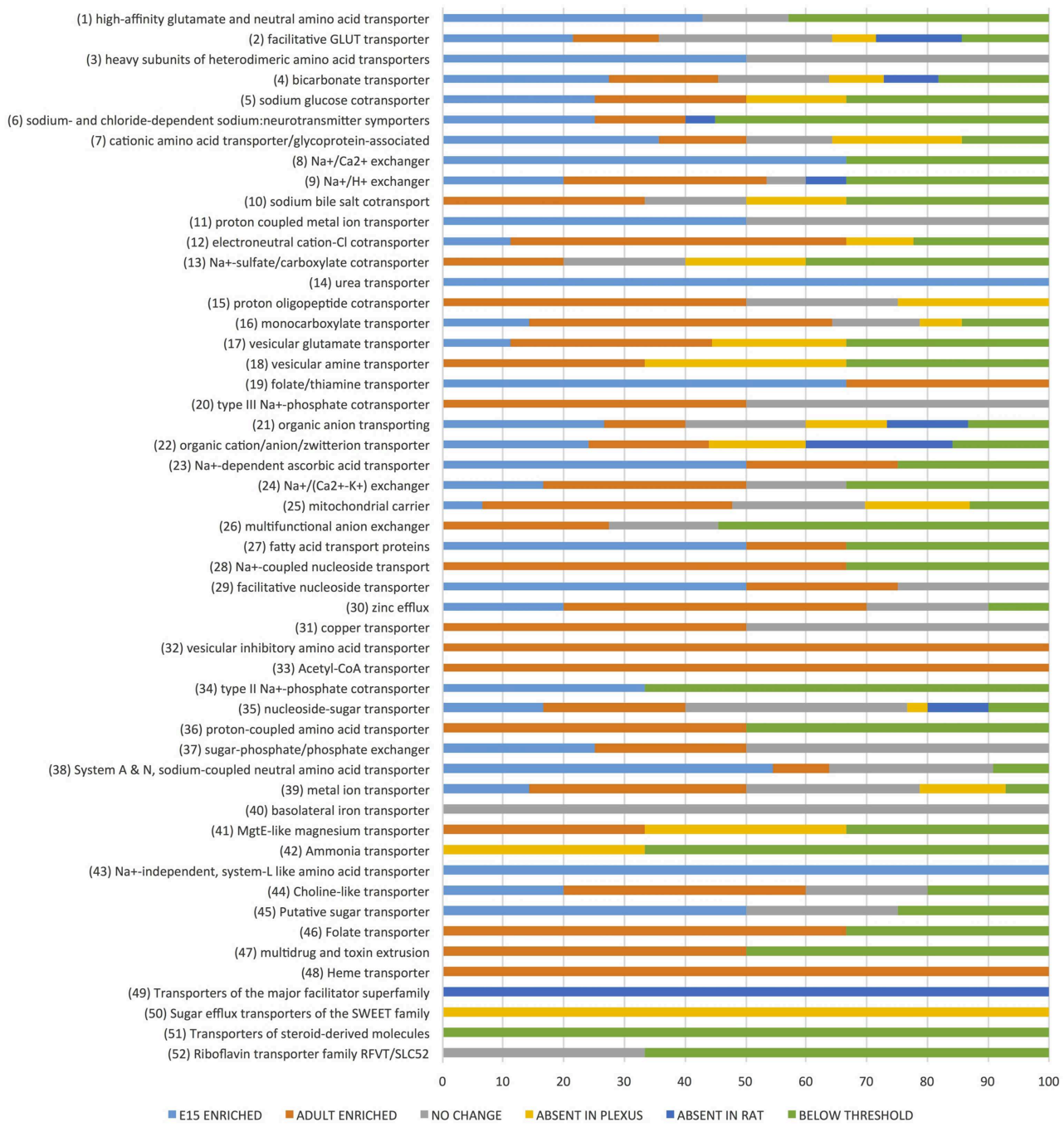

FIGURE 3 | SIc transporter genes identified in rat lateral ventricular choroid plexus. Expression of SLC family class transcripts in the embryonic and adult lateral ventricular choroid plexus as determined by RNA sequencing. Data are expressed as percentage total of each family of transporters. The 52 known functional groups of SLC transporters (Hediger, 2013) are shown on the left. The horizontal bars show the percentage of total number of members of each group identified "Enriched" refers to transcripts with greater than 2-fold expression in one age over the other, while "no change" refers to transcripts with similar expression at both ages. A transcript was considered absent in the choroid plexus if no single copy of transcript was detected (while those with "below threshold" had raw count values below 10). A transcript was considered absent in the rat if no annotation was found in the online ensemble database (http://www.ensembl.org/Rattus_norvegicus). "strong immunoreactivity, uniform distribution-type," "weak immunoreactivity, uniform distribution-type") and in 2 different patterns of immunoreactivity in adult plexus epithelial cells ("weak or lack of immunoreactivity," "strong immunoreactivity"). Representative micrographs from the 5 different patterns of immunoreactivity are shown in Figure 4.

\section{SLC 16a10}

An example of "differential immunoreactivity, regional distribution-type" is shown in E15 and of "weak or lack of immunoreactivity" is presented in adult plexus. The embryonic plexus epithelial cell layer in the "plexus-fold" next to the ganglionic eminence but opposite to the developing hippocampus showed a stronger immunostaining than the "plexus-fold" facing the hippocampus (Figure 4A). At high magnification the prominent reactivity in the epithelial cell layer facing the ganglionic eminence was shown to be due to a combination of a marked fine granular reactivity in apical cytoplasm and along both apical and basolateral cell membranes, which were particularly strongly immunostained (arrowheads in Figure 4A1). In contrast the epithelial cell layer facing the hippocampus showed a more uniform immunoreactivity both in cytoplasm and along cell membranes. Adult choroid plexus epithelial cells exhibited 
TABLE 2 | Expression and function of solute carrier (SIc) transcripts that were enriched in lateral ventricular choroid plexus of rat E15 and E19 embryos and P2 neonates compared to adult.

\begin{tabular}{|c|c|c|c|c|c|c|}
\hline Gene ID & Protein & Transport function & Ref. & E15/A & E19/A (E19/P2) & P2/A \\
\hline Slc16a10 & MCT10 & Aromatic AAs, T3, T4 & 1 & E & $P(2.1)$ & $P$ \\
\hline S/c38a5 & SN2, JM24, & $\mathrm{Na}^{+}$-dependent AAs & 2 & E & $P(0.6)$ & $P$ \\
\hline S/c43a3 & EEG1 & $\mathrm{Na}^{+}$-independent, L-like AAs & 2 & E & - & - \\
\hline Slc39a10 & ZIP10 & $\mathrm{Zn}^{2+}$ & & E & - & - \\
\hline S/c35f1 & FLJ13018 & Nucleoside-sugar & & 60 & - & - \\
\hline Slc4a1 & AE1, CD233 & Anion $\left(\mathrm{Cl}^{-}-\mathrm{HCO}_{3}\right.$ exchange $)$ & 6,7 & 59 & 6.4 & 3.4 \\
\hline Heph & Hephaestin & $\mathrm{Fe}^{2+}, \mathrm{Cu}^{2+}$ & & E & 6.1 & 6.3 \\
\hline S/c7a11 & $\mathrm{xCT}$ & Cysteine, glutamate & 2,5 & 44 & 24 & 5.4 \\
\hline S/c30a2 & ZnT2 & $\mathrm{Zn}^{2+}$ & 9 & E & $P(1.7)$ & $P$ \\
\hline Slc14a2_v1 & UTR, UT2 & Urea transport & & 39 & - & - \\
\hline S/c39a8 & ZIP8 & $\mathrm{Zn}^{2+}, \mathrm{Cd}^{2+}$ & 9 & 37 & $\mathrm{P}(1.3)$ & $P$ \\
\hline Slc6a4 & SERT & Na-dependent $5 \mathrm{HT}$ transport & & 35 & - & - \\
\hline Slc30a10* & ZnT10 & $\mathrm{Zn}^{2+}$ & & E & - & - \\
\hline S/c43a1 & LAT3 & Neutral AAs (phenylalanine) & 2 & E & $\mathrm{P}(0.8)$ & $\mathrm{P}$ \\
\hline S/c35f2 & FLJ13018 & Nucleotides into Golgi & & 19 & - & - \\
\hline Slc7a1 & CAT1 & Cationic AAs (arginine, lysine) & 2,5 & 16 & 11 & 3.7 \\
\hline Slc8a3 & NCX3 & $\mathrm{Na}^{+} / \mathrm{Ca} 2^{+}$exchanger & & 15 & - & - \\
\hline S/c38a1 & NAT2 & Glutamine ( $\mathrm{Na}^{+}$-dependent) & 3 & 15 & $P(1.0)$ & $P$ \\
\hline Slc6a6 & TAUT & Taurine, $\beta$-alanine & 2,5 & 14 & 6.9 & 6.1 \\
\hline Sfxn1 & Sideroflexin 1 & $\mathrm{Fe}^{2+}$ & & 14 & 8.1 & 7.2 \\
\hline Slc6a15 & BOAT2 & Neutral AAs & 2,5 & 14 & 9.8 & 4.3 \\
\hline S/c22a6* & OAT1, NKT & Organic anions ( $\mathrm{Na}^{+}$-dependent), kynurenic acid, $\mathrm{Hg}^{2+}$ & & 14 & - & - \\
\hline S/c23a1 & SVCT1 & Na dependent ascorbic acid & & 13 & - & - \\
\hline Slc39a11 & ZIP11 & $\mathrm{Zn}^{2+}$ transporter & & 12 & - & - \\
\hline Slc2a3 & GLUT3 & Glucose transporter & & 11 & 0.8 & 0.7 \\
\hline Slc5a7 & $\mathrm{CHT}$ & Choline, $\mathrm{Na}^{+}$/glucose co-transport & & 11 & - & - \\
\hline Slc17a6 & VGLUT2 & Glutamate & 3 & 9.1 & - & - \\
\hline Slc7a3 & САТЗ & Cationic amino acids & 2,5 & 9.1 & $P(1.0)$ & $P$ \\
\hline S/c11a1 & NRAMP & $\mathrm{Fe}^{2+}, \mathrm{Mn}^{2+}$, arginine & 10,11 & $\mathrm{E}$ & 1.6 & 1.4 \\
\hline Slc8a1 & NCX1 & $\mathrm{Na}^{+} / \mathrm{Ca}^{2+}$ exchanger & & 8.1 & - & - \\
\hline Slc27a6 & FATP6 & Long chain fatty acids & & 7.8 & - & - \\
\hline Slc45a3 & PROSTEIN & Putative sugar transporter & & 6.6 & - & - \\
\hline S/c34a2 & $\mathrm{NaPi}-\mathrm{Ilb}$ & $\mathrm{PO}_{4}^{3-}\left(\mathrm{Na}^{+}\right.$-dependent) & & 6.1 & $P(1.4)$ & $P$ \\
\hline Slc19a3 & THTR2 & Thiamine & & 6.0 & - & - \\
\hline Slco2a1 & PGT, OATP2A1 & Prostaglandin D2, E1, E2 and F2A, organic anions & & 5.7 & $\mathrm{P}(1.7)$ & $P$ \\
\hline S/c38a11 & - & $\mathrm{Na}^{+}$-dependent $\mathrm{AA} /$ proton antiporter (putative) & & 5.3 & - & - \\
\hline Slc5a8 & SMCT1 & Monocarboxylate transporter & & 5.2 & - & - \\
\hline Slc16a14 & MCT14 & Monocarboxylate transporter & & 5.2 & - & - \\
\hline Slc38a4 & ATA3 & Acidic and neutral AAs & 2. 3,5 & 5.2 & - & - \\
\hline S/c35d2 & HFRC & Nucleotide sugars & & 5.1 & - & - \\
\hline Slc1a4 & SATT & Glutamate, neutral AAsalanine, serine, cysteine, threonine & 3,4 & 5.1 & - & - \\
\hline Slc1a3 & GLU-T & Glutamate, neutral AAs & 3,4 & 4.5 & 3.3 & 2.8 \\
\hline Slc6a13 & GAT3 & GABA transporter & 8 & 4.4 & $P(0.4)$ & $P$ \\
\hline Slc9a5 & NHE5 & $\mathrm{Na}^{+} / \mathrm{H}^{+}$exchanger & 6,7 & 4.4 & $P(0.9)$ & $P$ \\
\hline Slc37a2 & SPX2 & Glucose-6-phosphate antiporter & & 4.2 & - & - \\
\hline Slc4a4 & NBC1 & Electrogenic $\mathrm{NaHCO}_{3}$ & 6,7 & 3.9 & - & - \\
\hline LOC100360087 & Ferritin Light Chain, Flt1-like & $\mathrm{Fe}^{3+}$ storage & & 3.6 & 2.4 & 1.7 \\
\hline S/c22a2 & ОСТ2 & Organic cations, anions, zwitterions & & 3.4 & - & - \\
\hline S/c29a2 & ENT2 & Nucleosides & & 3.2 & 1.2 & 1.1 \\
\hline Trfr & TFR & Transferrin receptor & & 3.1 & 0.5 & 0.6 \\
\hline
\end{tabular}


TABLE 2 | Continued

\begin{tabular}{|c|c|c|c|c|c|c|}
\hline Gene ID & Protein & Transport function & Ref. & E15/A & E19/A (E19/P2) & P2/A \\
\hline Slc2a1 & GLUT1 & Glucose & & 3.0 & 1.9 & 0.9 \\
\hline S/c27a3 & FATP3 & Long-chain fatty acids & & 2.9 & 2.3 & 2.9 \\
\hline Slc24a6 & - & $\mathrm{Na}^{+} / \mathrm{Li}^{2+} / \mathrm{Ca}^{2+}$ exchanger & & 2.8 & 1.2 & 1.2 \\
\hline Slc7a2 & CAT2 & Low affinity cationic AAs & & 2.7 & $\mathrm{P}$ & - \\
\hline Slc4a3 & AE3 & Anion exchange & 6,7 & 2.7 & 0.6 & 0.8 \\
\hline Slc25a27 & UCP4 & Mitochondrial uncoupling protein & & 2.7 & - & - \\
\hline Slc38a7 & SNAT7 & Putative $\mathrm{Na}^{+}$-coupled neutral AAs & & 2.7 & - & - \\
\hline S/c22a15 & FLIPT1 & Organic cations, anions, zwitterions & & 2.6 & 2.1 & 1.8 \\
\hline Slc35e1 & FLJ14251 & Nucleotide sugars & & 2.5 & 1.2 & 0.9 \\
\hline Slc22a9 & OAT7 & Organic anions & & 2.5 & - & - \\
\hline Slc14a1 & UT-B1-B2 & Urea & & 2.4 & - & - \\
\hline S/c22a23 & - & Organic cations, anions, zwitterions & & 2.4 & 1.7 & 1.0 \\
\hline Slc43a2 & LAT4 & Large neutral AAs & & 2.4 & 1.3 & 1.4 \\
\hline Slco2b1 & OATP2B1 & Organic anions & & 2.4 & 2.3 & 2.3 \\
\hline S/c29a3 & ENT3 & Nucleosides & & 2.1 & 0.8 & 0.7 \\
\hline Slc1a5 & ASCT2 & Neutral AAs & 3,4 & 2.1 & 0.8 & 0.7 \\
\hline
\end{tabular}

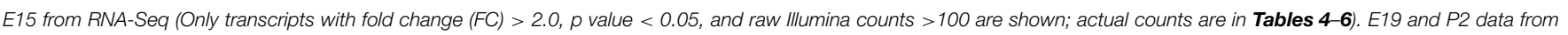

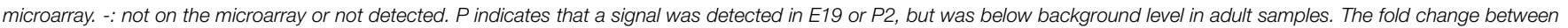

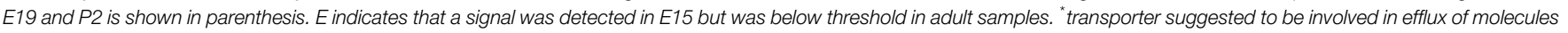

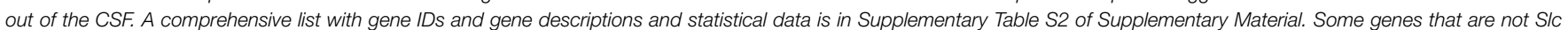

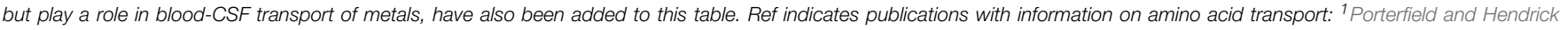

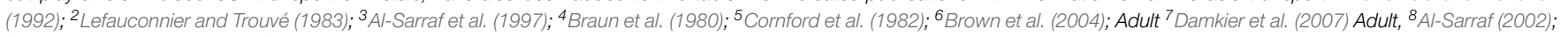
${ }^{9}$ Chowanadisai et al. (2005); ${ }^{10}$ Moos and Morgan (1998); ${ }^{11}$ Morgan and Moos (2002).

virtually no immunostaining of either membranes or cytoplasm (Figure 4B).

\section{SLC1a3}

This protein showed an example of "strong immunoreactivity," uniform distribution type at E15 and of "weak or lack of immunoreactivity" in adult plexus. Both embryonic plexus epithelial cell layers of the "plexus-fold"-the leaflet next to the ganglionic eminence and the other next to the developing hippocampus - showed a strong uniform cytoplasmic immunostaining (Figure 4C). At high magnification the prominent reactivity was shown to be due to a combination of a marked fine granular reactivity in apical cytoplasm and along both apical and basolateral cell membranes, which were particularly strongly immunostained (arrowheads in Figure 4C1) comparable to those stained for SLC16a10 in the plexus fold next to the ganglionic eminence shown in Figure 4A1. Adult choroid plexus epithelial cells showed virtually no cytoplasmic immunostaining and a lack of apical and basolateral cell membrane immunoreactivity (Figure 4D).

\section{SLC5a5}

Shown as an example of "weak immunoreactivity," uniform distribution at E15 and of "strong immunoreactivity" in adult plexus. Embryonic plexus epithelial cells showed no cytoplasmic reactivity and no immunostaining of the apical cell membrane in marked contrast to the adjacent strongly stained CSFhippocampal interface (Figure 4E). A weak basolateral cell membrane staining of plexus epithelial cells could be identified at high magnification (arrowheads in Figure 4E1). Adult choroid plexus exhibited a uniform fine and coarse granular cytoplasmic staining of most epithelial cells (open arrows in Figure 4F) and a distinct apical membrane staining (arrowheads in Figure 4F).

\section{SLC39a4 (ZIP4), SLC38a5 (SNAT5), SLC4a1 (AE1), SLC11a1 (NRAMP)}

Following immunostaining for SLC39a4 plexus epithelial cells were characterized by "weak immunoreactivity," uniformly distributed in both E15 and adult plexus, whereas staining for SLC38a5, SLC4a1, and SLC11a1 resulted in immunoreactivity of the uniform distribution-type, however stronger along the basal and basolateral cell membrane in E15, and very little cytoplasmic staining and virtually no basolateral or apical membrane staining in adult plexus apart from SLC38a5 which showed a patchy immunostaining of the apical cell membrane (data not shown).

\section{Discussion}

All but four of the 52 known families of SCL transporters were represented in the dataset from RNA sequencing of lateral ventricular choroid plexuses in the rat embryo (E15) and in the adult (Supplementary Table S1). Of the 389 individual SCLs, $64 \%$ had transcript numbers above the threshold taken to indicate likely functional significance ( $>100$ sequence reads). 81 of these were expressed 2 fold higher or more in the embryonic plexus compared to the adult, 107 were expressed higher in the adult and 62 were expressed at similar levels at the two ages. Some genes were identifiable with transcript counts of 10-100, but thought less likely to be of functional significance; they have nonetheless been included in Tables 4-6. The results for 
TABLE 3 | Expression and function of solute carrier (SIc) transcripts that were enriched in lateral ventricular choroid plexus of adult rats compared to E15 RNA-Seq) and E19 and P2 (microarray).

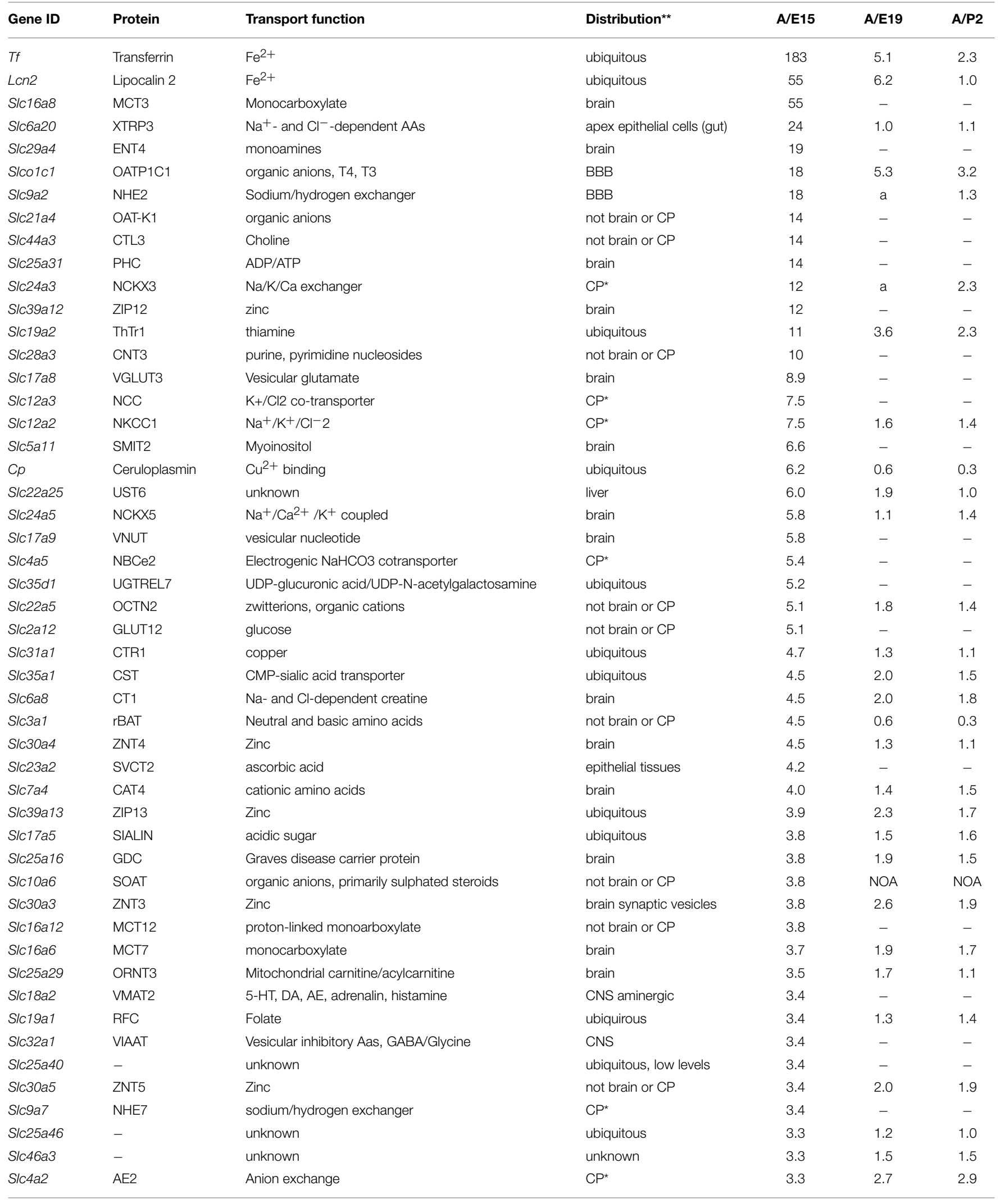


TABLE 3 | Continued

\begin{tabular}{|c|c|c|c|c|c|c|}
\hline Gene ID & Protein & Transport function & Distribution** & A/E15 & A/E19 & A/P2 \\
\hline Slc5a6 & SMVT & Sodium-dependent multivitamin, biotin & brain & 3.2 & 1.7 & 1.5 \\
\hline Slc25a17 & PMP34 & peroxisomal membrane protein & brain & 3.1 & 1.6 & 1.5 \\
\hline Slc15a3 & PHT2 & di- and tri-peptides & "faintly" in brain & 3.1 & - & - \\
\hline Slc12a4 & KCC1 & $\mathrm{K}^{+} / \mathrm{Cl}^{-}$ & $\mathrm{CP}^{*}$ & 3.1 & 2.2 & 2.0 \\
\hline Slc10a4 & P4 & Sodium/bile acid cotransporter & brain (cholinergic neurons) & 3.0 & - & - \\
\hline S/c25a12 & AGC1 & L-glutamate, aspartate & brain & 3.0 & 1.9 & 1.8 \\
\hline Slc25a3 & $\mathrm{PHC}$ & Phosphate, mitochondrial & brain & 2.9 & 1.3 & 1.2 \\
\hline Slc26a3 & DRA/CLD & Chloride anion exchanger & not brain or $\mathrm{CP}$ & 2.9 & - & - \\
\hline Slc25a4 & ANT1 & ADP/ATP & brain & 2.9 & 1.1 & 1.1 \\
\hline Slc15a2 & PEPT2 & Oligopeptides, antibiotics & choroid plexus apical surface & 2.8 & 0.7 & 0.8 \\
\hline S/c25a5 & ANT2 & ADP/ATP & brain & 2.8 & 1.2 & 1.2 \\
\hline S/c38а3 & SNAT3 & Sodium-coupled neutral amino acids & not brain or CP & 2.7 & 1.2 & 1.2 \\
\hline Slc25a14 & UCP5 & Brain mitochondrial carrier protein & highest in brain and testis & 2.7 & 1.6 & 1.4 \\
\hline S/c30a6 & ZNT6 & Zinc & brain & 2.7 & 1.3 & 1.1 \\
\hline S/c22a18 & - & Probably organic anions & not brain or $\mathrm{CP}$ & 2.6 & 1.4 & 1.6 \\
\hline Slc37a1 & SPX1 & Glycerol-3-phosphate & ubiquitous & 2.6 & 2.1 & 1.4 \\
\hline Slc25a35 & - & unknown & unknown & 2.6 & - & - \\
\hline Slc33a1 & ACATN1 & Acetyl-coenzyme A & brain & 2.6 & 1.4 & 1.3 \\
\hline Slc36a1 & PAT1 & Neutral amino acids, glycine, proline, GABA & brain & 2.4 & - & - \\
\hline Slc16a1 & MCT1 & Monocarboxylates & ubiquitous & 2.4 & 3.1 & 1.4 \\
\hline Slc20a1 & PIT1 & Sodium-dependent phosphate & ubiquitous & 2.4 & 1.7 & 2.0 \\
\hline Slc36a4 & PAT4 & Proton-coupled AAs, tryptophan, proline & ubiquitous & 2.3 & - & - \\
\hline Slc48a1 & HRG1 & Heme transporter & brain & 2.3 & 1.9 & 1.3 \\
\hline S/c25a32 & MFT & Mitochondrial folate & unknown & 2.3 & 1.1 & 1.0 \\
\hline Slc41a1 & MgtE & $\mathrm{Mg}^{2+}$, other metal cations & not brain or $\mathrm{CP}$ & 2.3 & a & 1.7 \\
\hline Slc16a13 & MCT13 & Monocarboxylate & not brain or CP & 2.3 & 1.9 & 1.7 \\
\hline Slc26a4 & PENDRIN & Anions & epithelial cells & 2.2 & - & - \\
\hline Slc16a2 & MCT8 & Monocarboxylate transporter 8, thyroxine & brain & 2.1 & - & - \\
\hline Slc25a20 & CACT & Mitochondrial carnitine/acylcarnitine & brain & 2.1 & 1.1 & 0.9 \\
\hline S/c35b3 & PAPST2 & Adenosine 30-phospho 50-phosphosulphate & ubiquitous & 2.1 & 1.7 & 1.5 \\
\hline Slc7a10 & ASC1 & Asc-type amino acids, D-serine & brain & 2.1 & 0.6 & 0.8 \\
\hline Slc31a2 & CTR2 & $\mathrm{Cu}^{2+}$ & ubiquitous & - & 1.7 & 1.0 \\
\hline
\end{tabular}

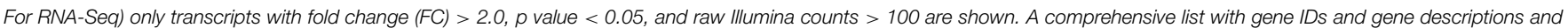

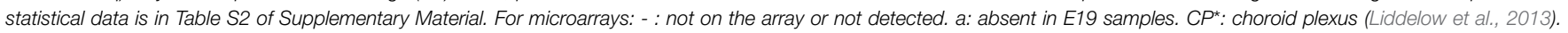

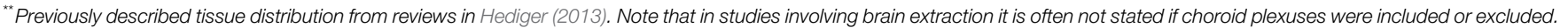

microarray were generally consistent with those for RNA-Seq in their developmental profile.

It is apparent from the above analysis that many genes identified are from families involved in transport of ions important for homeostatic mechanisms in the CSF and interstitial fluid of the brain (Tables 2, 3, and Supplementary Tables S2, S3). The monovalent inorganic ion transporters known to be functionally active in adult choroid plexus and involved in CSF composition and secretion have been described in detail and their expression levels correlated with functional data in the paper by Liddelow et al. (2013). Divalent metal ions such as $\mathrm{Ca}^{2+}$, $\mathrm{Zn}^{2+}$, and $\mathrm{Mg}^{2+}$ may be involved in specific cellular functions in brain such a synaptic transmission of nerve impulses and are considered briefly below.

The immunohistochemical data presented above indicate that at least some of the most highly expressed Slc genes are able to produce their protein products. A more difficult problem is to establish the functional effectiveness of individual Slcs for example for glucose, particular amino acids or specific monocarboxylates. This is because of the overlap in substrates between many SLCs (see Tables 2, 3). Because of this and of upregulation of unaffected genes, even selective knockouts of single genes may not reveal the contribution of that particular gene to the transport of specific substrates (see Keep and Smith, 2011). However, it is possible to suggest that at least some of the genes are indeed functionally more active in embryonic choroid plexus by examining results of transport studies for glucose, amino acids, monocarboxylates, and divalent cations in developing brain.

\section{Glucose Transport}

The best known and ubiquitously distributed glucose transporter Slc2a1 (GLUT1) was expressed at a 3-fold higher level in the embryonic choroid plexus at transcript levels (Table 4) 
TABLE 4 | Glucose and Monocarboxylate transporters in developing rat choroid plexus.

\begin{tabular}{|c|c|c|c|c|}
\hline \multirow[t]{2}{*}{ Gene name } & \multirow[t]{2}{*}{ Gene description } & \multirow[t]{2}{*}{ FC } & \multicolumn{2}{|c|}{ Raw transcript counts } \\
\hline & & & EMBRYO (E15) & ADULT \\
\hline \multicolumn{5}{|c|}{ GLUCOSE TRANSPORTERS } \\
\hline Embryo & & E/A & & \\
\hline Slc5a10 & Slc family 5 , sodium/glucose cotransporter 10 & $E$ & 62 & 0 \\
\hline Slc2a3 & Slc family 2, facilitated glucose transporter 3, GLUT3 & $E$ & 150 & 8 \\
\hline Slc2a4 & Slc family 2, facilitated glucose transporter 4, GLUT4 & $E$ & 90 & 6 \\
\hline Slc35d2 & UDP-N-acetylglucosamine/UDP-glucose/GDP-mannose & 5.1 & 224 & 25 \\
\hline Slc45a1 & Proton-associated sugar transporter A, glucose & $E$ & 33 & 5 \\
\hline Slc2a1 & Slc family 2, facilitated glucose transporter 1, GLUT1 & 3.0 & 368 & 111 \\
\hline Adult & & A/E & & \\
\hline Slc2a12 & Slc family 2 , facilitated glucose transporter 12 , GLUT12 & 5.1 & 3569 & 10437 \\
\hline Slc2a5 & Slc family 2, facilitated glucose transporter 5, GLUT5 & 2.3 & 20 & 27 \\
\hline Klf15 & Krueppel-like factor 15, regulator of GLUT4 & 2.2 & 292 & 373 \\
\hline \multicolumn{5}{|c|}{ MONOCARBOXYLATE TRANSPORTERS } \\
\hline Embryo & & E/A & & \\
\hline Slc16a10 & Monocarboxylate transporter 10, MCT10, TAT1, T3, T4 & $E$ & 3089 & 51 \\
\hline Adult & & A/E & & \\
\hline Slc16a8 & Monocarboxylate transporter 3, МСT3 & 55 & 49 & 1524 \\
\hline Slc16a6 & Monocarboxylate transporter 7, MCT6, MCT7 & 3.7 & 1524 & 3239 \\
\hline Slc16a1 & Monocarboxylate transporter 1, MCT1 & 2.4 & 577 & 1235 \\
\hline Slc16a7 & Monocarboxylate transporter 2, MCT2 & 2.3 & 44 & 58 \\
\hline Slc16a13 & Monocarboxylate transporter 13, MCT13-human & 2.3 & 1354 & 1756 \\
\hline Slc16a2 & Monocarboxylate transporter 8, MCT8-human, thyroid hormone & 2.1 & 7599 & 9323 \\
\hline
\end{tabular}

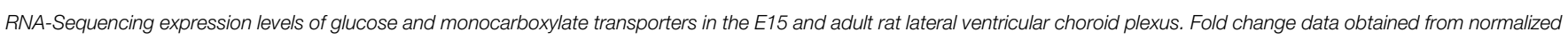

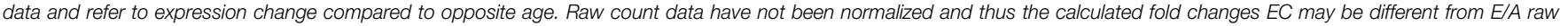
count ratios. E is embryo only. $A$ is adult only.

suggesting that it would have significant functional activity at both ages, although higher in the embryo. It has been identified in developing choroid plexus in a number of previous studies (Vannucci, 1994; Baud et al., 2003); the level was highest during gestation followed by a $50 \%$ decline by P1 and a further decline during the first postnatal week (Bauer, 1998). Bauer (1998) suggests this reflects a decline in cerebral glycogen content (Kohle and Vannucci, 1977). Glycogen is particularly prominent in choroid plexus epithelial cells in the late embryonic and early neonatal period, after which it disappears (Schachenmayr, 1967 and see Netsky and Shuangshoti, 1975). Slc2a3 (GLUT3) in the present study was expressed only at E15 in RNA-Seq compared to adult and in microarray was below adult at E19 and P2. The protein product of this gene was not identified in a previous study of postnatal rat choroid plexus (Vannucci, 1994). Slc2a4 (GLUT4) was also expressed only in the embryo, although at a low transcript count (90). This appears to be consistent with the finding of Vannucci et al. (2000) in mouse choroid plexus where it was detected as early as at E14. In addition, in the present study Slc5a10 (SGLT5), a sodium-glucose transporter was expressed exclusively in the embryonic choroid plexus. Previously it has only been identified in kidney cortex (Wright, 2013). However, the raw transcript count for this gene was low, thus its functional significance is unclear.

\section{Monocarboxylate Transport}

It has been long accepted that although glucose is a fundamentally important energy substrate in the brain, during development the brain also uses lactate and other monocarboxylates to a substantial degree. In the postnatal period in rodents it has been suggested that a switch occurs from a combination of glucose, lactate, and ketone body metabolism in the immature brain to a reliance on glucose in the adult (Cremer, 1982; Nehlig, 1997). Several monocarboxylate transporters have been found in the developing brain of rodents. Slc16a1 (MCT1) is expressed and its protein product present in cerebrovascular endothelial cells of rodents at higher levels in early postnatal ages compared to later (Leino et al., 1999; Vannucci and Simpson, 2003). In contrast the level of Slc16a7 (MCT2) expression and protein product, present predominantly in neuronal cells, do not appear to be developmentally regulated (Vannucci and Simpson, 2003). Slc16a1 (MCT1), but not Slc16a7 (MCT2), has been 
TABLE 5 | Expression of amino acid transporters in embryonic (E15) and adult rat choroid plexus.

\begin{tabular}{|c|c|c|c|c|}
\hline \multirow[t]{2}{*}{ Gene name } & \multirow[t]{2}{*}{ Gene description } & \multirow[t]{2}{*}{ FC } & \multicolumn{2}{|c|}{ Raw transcript counts } \\
\hline & & & EMBRYO (E15) & ADULT \\
\hline \multicolumn{5}{|c|}{ AMINO ACID TRANSPORTERS } \\
\hline Embryo & & E/A & & \\
\hline S/c38a5 & Sodium-coupled neutral amino acid transporter 5, glycine & $E$ & 1021 & 6 \\
\hline S/c43a3 & Putative transporter (by similarity) & $E$ & 914 & 8 \\
\hline Slc7a11 & Solute carrier family 7 (cationic amino acid transporter, y+ system), member 11 & 44 & 13298 & 178 \\
\hline Slc43a1 & Large neutral amino acids transporter small subunit 3 & $E$ & 204 & 5 \\
\hline Slc7a1 & High affinity cationic amino acid transporter 1 & 16 & 7273 & 264 \\
\hline Slc38a1 & Sodium-coupled neutral amino acid transporter 1, glutamine & 15 & 1188 & 47 \\
\hline Slc6a6 & Sodium- and chloride-dependent taurine transporter & 14 & 813 & 33 \\
\hline Slc6a15 & Orphan sodium- and chloride-dependent neurotransmitter transporter NTT73 & 14 & 5446 & 227 \\
\hline S/c7a3 & Cationic amino acid transporter 3, I-lysine, I-ornithine, I-arginine & 9.1 & 42.0 & 2.7 \\
\hline Slc38a4 & Sodium-coupled neutral amino acid transporter 4 & 5.2 & 102 & 11 \\
\hline Slc1a4 & Neutral amino acid transporter A, I-serine, I-alanine, I-cystine, I-proline, & 5.1 & 436 & 49 \\
\hline Slc1a3 & Excitatory amino acid transporter 1, I-glutamate transport, malate-aspartate & 4.5 & 4372 & 577 \\
\hline Slc7a2 & Low affinity cationic amino acid transporter 2, I-arginine, I-lysine, I-ornithine & 2.7 & 179 & 38 \\
\hline S/c38a7 & Putative sodium-coupled neutral amino acid transporter 7 & 2.7 & 337 & 73 \\
\hline S/c43a2 & Large neutral amino acids transporter small subunit 4 & 2.4 & 651 & 156 \\
\hline Slc1a5 & Neutral amino acid transporter B(0) I-serine, & 2.1 & 1119 & 308 \\
\hline Adult & & A/E & & \\
\hline Slc6a20 & Sodium- and chloride-dependent transporter XTRP3, proline IMINO transporter & 24 & 44 & 594 \\
\hline Slc6a11 & Sodium- and chloride-dependent GABA transporter 3 & 5.0 & 10 & 28 \\
\hline S/c3a1 & Neutral and basic amino acid transport protein rBAT & 4.5 & 746 & 1936 \\
\hline Slc7a4 & Cationic amino acid transporter 4 & 4.0 & 706 & 1618 \\
\hline S/c38a3 & Sodium-coupled neutral amino acid transporter 3. I-asparagine, I-glutamine, I-histidine & 2.7 & 4507 & 6922 \\
\hline Slc36a1 & Proton-coupled neutral amino acid transporter 1, I-glycine, I-proline & 2.4 & 97 & 136 \\
\hline Slc36a4 & Proton-coupled amino acid transporter 4 & 2.3 & 718 & 969 \\
\hline Slc7a10 & Asc-type neutral amino acid transporter 1 , d-serine, I-serine & 2.1 & 783 & 935 \\
\hline
\end{tabular}

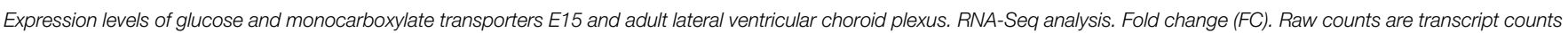

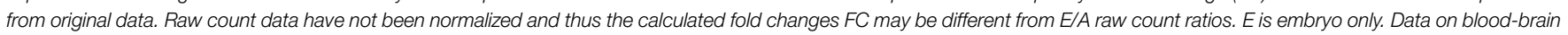

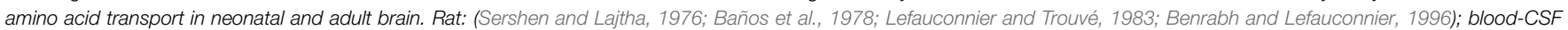

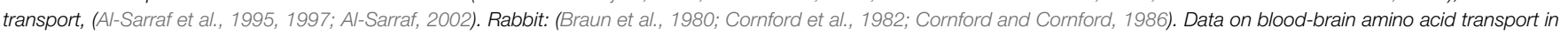
adult brain. (Davson and Segal, 1996; Segal, 2001).

identified in adult mouse choroid plexus (Koehler-Stec et al. (1998).

The expression of monocarboxylate transporters appears to have been less studied in the embryonic brain barrier interfaces. Apart from a high expression of Slc16a10 (MCT10) in embryonic mouse choroid plexus (Liddelow et al., 2012) nothing seems to be known about monocarboxylate transporters in the embryonic choroid plexus. This high expression in embryonic mouse choroid plexus is confirmed in the present study for embryonic rat choroid plexus. This is a particularly noteworthy finding because MCT10 is a transporter for tri-iodothyronine, T3 and thyroxine, T4 (Porterfield and Hendrick, 1992), which are essential for normal brain development. Inadequate delivery of T4 to the developing brain, usually due to iodine deficiency, results in cretinism (Rivas and Naranjo, 2007; Skeaff, 2011). Given the prominence of the choroid plexuses in the embryonic brain compared to vascularisation (Johansson et al., 2008), it may be that MCT10 in the choroid plexuses along with TTR, a thyroid hormone carrier highly expressed throughout development, is the major mechanism by which thyroxine is delivered to the brain in early stages of its development. This is also in line with the low developmental expression of Slco1c1, the main thyroid hormone transporter expressed at the blood-brain interfaces in the adult (Kratzer et al., 2013).

Published data demonstrating at the protein level, that some of the glucose transporters (Vannucci, 1994; Bauer, 1998; Baud et al., 2003) and monocarboxylate transporters (Leino et al., 1999; Vannucci and Simpson, 2003) are present in the choroid plexus barrier interface between blood and CSF in the developing brain indicate that these transporters are probably functional. In addition, it has been shown that brain uptake of both glucose (Braun et al., 1980; Cornford and Cornford, 1986) 
TABLE 6 | Expression of zinc and other metal transporters in embryonic (E15) and adult rat choroid plexus.

\begin{tabular}{|c|c|c|c|c|}
\hline Gene name & Gene description & FC & \multicolumn{2}{|c|}{ Raw transcript counts } \\
\hline \multicolumn{5}{|l|}{ EMBRYO } \\
\hline ZINC & & E/A & & \\
\hline S/c30a2 & Zinc transporter 2, ZnT2 & $\mathrm{E}$ & 608 & 8 \\
\hline S/c39a8 & Zinc transporter ZIP8 & 37 & 1493 & 24 \\
\hline S/c39a10 & Zinc transporter, 10 (Predicted), ZIP10 & 2.5 & 5547 & 1304 \\
\hline \multicolumn{5}{|l|}{ OTHER METALS } \\
\hline Sfxn1 & Sideroflexin-1, iron transport & 14 & 1103 & 45 \\
\hline Slc11a1 & Natural resistance-associated macrophage protein $1, \mathrm{Mn}+, \mathrm{Cd}+$ transporter & E & 130 & 8 \\
\hline \multicolumn{5}{|l|}{ ADULT } \\
\hline ZINC & & A/E & & \\
\hline Slc39a1 & ZIP1, zinc transport & 12 & 2143 & 17839 \\
\hline Slc39a12 & Zinc transporter ZIP12 & 12 & 489 & 3318 \\
\hline Slc30a4 & Zinc transporter 4, ZnT4 & 4.5 & 2025 & 5248 \\
\hline S/c39a13 & Zinc transporter ZIP13 & 3.9 & 758 & 1681 \\
\hline Slc30a3 & Zinc transporter 3, ZnT3 & 3.8 & 54 & 117 \\
\hline S/c30a5 & Zinc transporter 5, Co, ZnT5 & 3.4 & 1397 & 2719 \\
\hline S/c30a6 & Zinc transporter 6, Co, ZnT6 & 2.7 & 491 & 752 \\
\hline
\end{tabular}

\section{OTHER METALS}

\begin{tabular}{|c|c|c|c|c|}
\hline$T f$ & Transferrin, iron transport & 183 & 2027 & 212407 \\
\hline Lcn2 & Lipocalin 2, Signal recognition particle receptor subunit beta, iron transport & 55 & 12 & 365 \\
\hline$C p$ & Ceruloplasmin copper transport & 6.2 & 188 & 675 \\
\hline Slc31a1 & High affinity copper uptake protein 1 & 4.6 & 6673 & 17839 \\
\hline Slc41a1 & MgtE-like magnesium transporter, member 1 & 2.3 & 401 & 530 \\
\hline \multicolumn{5}{|c|}{ NO CHANGE WITH AGE } \\
\hline S/c30a6 & ZNT6, zinc transport & - & 491 & 752 \\
\hline Slc30a7 & ZNT7, zinc transport & - & 424 & 400 \\
\hline Slc30a9 & ZNT9, zinc transport & - & 1512 & 1526 \\
\hline S/c39a3 & ZIP3 zinc transport & - & 322 & 315 \\
\hline S/c39a4 & ZIP4, zinc transport & - & 58 & 38 \\
\hline Slc11a2 & DMT1, divalent ion transport, including iron & - & 1929 & 1518 \\
\hline \multicolumn{5}{|c|}{ OTHER METALS } \\
\hline Slc40a1 & iron-regulated transporter & - & 889 & 455 \\
\hline Slc31a2 & CTR2, copper transport & - & 63 & 144 \\
\hline S/c41a2 & magnesium transporter & - & 20 & 63 \\
\hline
\end{tabular}

Expression levels of $\mathrm{Zn}$ and other metal transporters comparing $E 15$ embryo and adult lateral ventricular choroid plexus obtained from RNA-Seq analysis. Fold change ( $F C$ ), Embryo only (E). Raw counts are transcript counts from original data. Raw count data have not been normalized and thus the calculated fold changes FC may be different from E/A raw count ratios. 

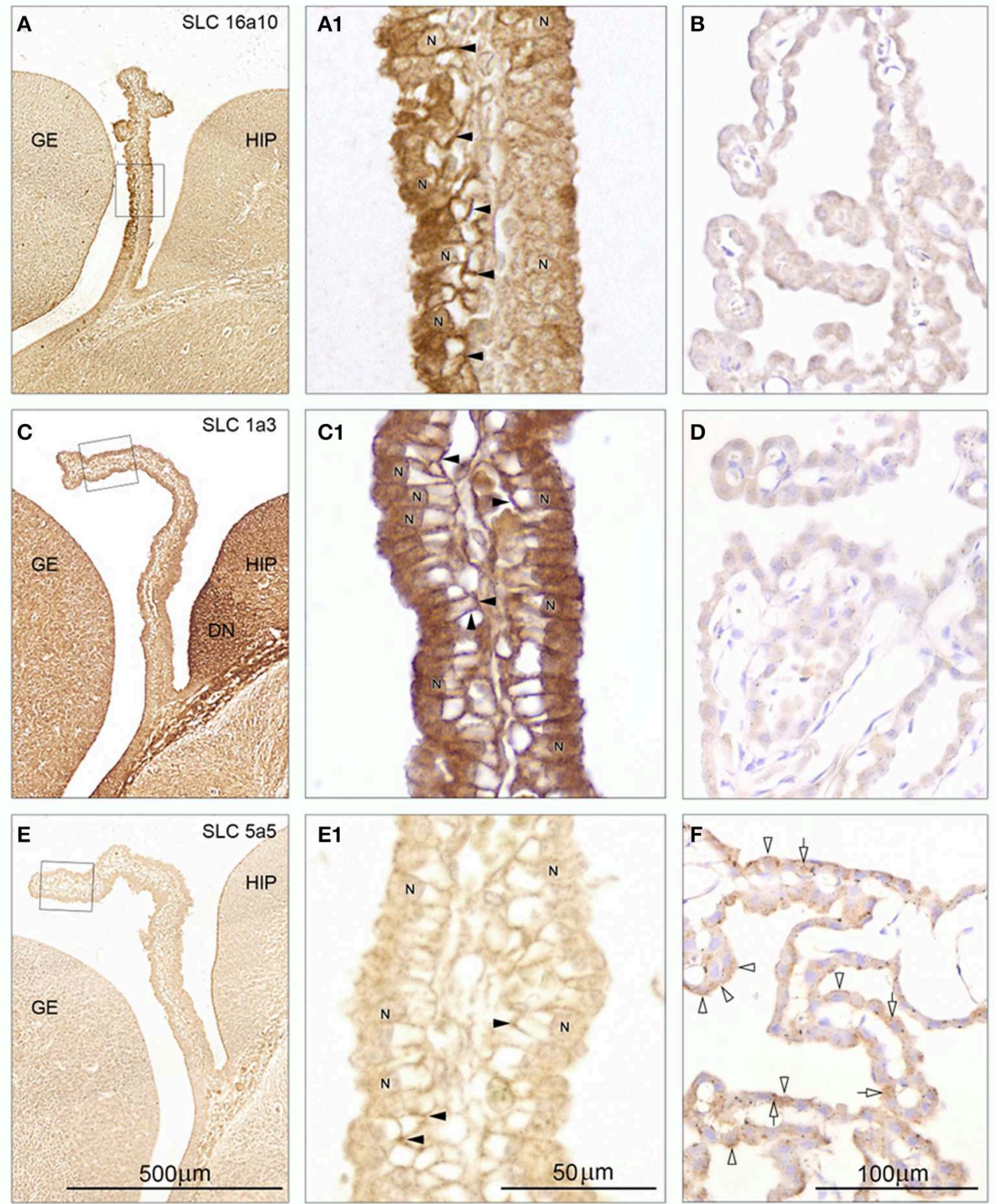

FIGURE 4 | Immunohistochemistry of influx transporters in sagittal and coronal sections from $\mathrm{E} 15$ and adult rat choroid plexus: SLC 16a10 (A,A1,B), SLC 1a3 (C,C1,D), and SLC 5a5 (E,E1,F). The rectangles in $(\mathbf{A}, \mathbf{C}, \mathbf{E})$ from $\mathrm{E} 15$ are shown at higher magnification in $\mathbf{A 1}, \mathbf{C 1}, \mathbf{E 1}$. For comparison adult choroid plexus stained for the same three transporters is shown in $\mathbf{B , D}, \mathbf{F}$. Note the differences in distribution of immunoreactivity between E15 stained for the three different transporters and between E15 and adult choroid plexus stained for a given transporter. (A) The rostral-most leaflet of the lateral ventricular choroid plexus facing the ganglionic eminence (GE) demonstrates a very strong reactivity in contrast to the caudal-most leaflet facing the developing hippocampus (HIP). (A1) At higher magnification the Immunostaining fills the entire cytoplasm apical to the nuclei $(\mathrm{N})$ and down along the basolateral membrane (arrowheads) just sparing the empty glycogen space in the epithelial cells of the rostral leaflet. The caudal leaflet is also positively stained and shows a more uniform cytoplasmic reactivity although condensed at the perinuclear membrane. (B) Adult choroid plexus shows virtually no immunostaining for SLC 16a10. (C) Both leaflets of the choroid plexus demonstrate a uniform cytoplasmic immunoreactivity for SLC 1a3 although not as strong as that of the adjacent dentate neuroepithelium (DN). (C1) At higher magnification the immunostaining of the entire plexus shows a pattern similar to that described for the rostral leaflet stained for SLC 16a10 (compare with A1). (D) Adult choroid plexus shows virtually no immunostaining for SLC 1 a3. (E) The E15 choroid plexus shows very little immunoreactivity following staining for SLC $5 \mathrm{a} 5$ which on the other hand outlines the CSF surface of the hippocampus. (E1) At higher magnification a weak Immunostaining is localized to some basolateral cell membranes (arrowheads) of the choroid plexus epithelial cells. (F) Adult choroid plexus epithelial cells exhibit a uniform very fine granular cytoplasmic reactivity following immunostaining for SLC 5a5. Many cells also exhibit a coarse granular staining (open arrows) and apical membrane reactivity (open arrowheads). (A,C,E) Same magnification, scale bar $500 \mu \mathrm{m}$. (A1,C1,E1) Same magnification, scale bar $50 \mu \mathrm{m}$. (B,D,F) Same magnification, scale bar $100 \mu \mathrm{m}$. 
and lactate (Cornford et al., 1982; Cornford and Cornford, 1986) is greater in newborn rabbits than in adults, which again supports the likelihood that transporters for these metabolically important nutrients are indeed functionally more active in the developing brain. It is not clear from the transport studies, which specific glucose transporters would have been involved, but the transcript numbers perhaps give some indication of the relative functional importance of the different transporters. The most highly expressed glucose transporter at both ages was Slc2a12, although 5 fold more in the adult.

The finding in the present study of a high expression of glucose transporters in the embryonic brain, but not of those transporting lactate and other monocarboxylates, suggests that the embryonic brain is like the adult brain in being exclusively dependent on glucose metabolism as a source of energy, as suggested previously by Vannucci and Vannucci (2000) and unlike the postnatal brain in which monocarboxylate transport should be functionally significant. However, of all the monocarboxylate transporters detected on the arrays, three genes, Slc16a3, Slc16a4 (not detected by RNA-Seq) and Slc16a10, were expressed at a higher level at E19 than at P2 and adult, and the others were expressed at a higher level in adult. It is possible that a transient up-regulation occurs later in post-natal development for some of these transporters. This was shown for Slc16a1 (MCT1) in the postnatal period at least in rodents, and may relate to the high fat content in human and rodent maternal milk, which generates substantial ketone body concentrations in blood, as a consequence of liver metabolism (Vannucci and Vannucci, 2000; Vannucci and Simpson, 2003).

\section{Amino Acid Transport}

There is a limited amount of information concerning the effectiveness of amino acid transport in vivo, that could support expression data. Experiments mainly carried out in the 1970s80 s were mostly performed in neonatal rats (e.g., Baños et al., 1978; Lefauconnier and Trouvé, 1983, see Table 6) but some were in fetal and postnatal rabbits (Braun et al., 1980; Cornford et al., 1982; Cornford and Cornford, 1986). Very few of these studies estimated amino acid entry from blood into CSF. Most studied brain tissue; an exception is the papers of Al-Sarraf and colleagues (Al-Sarraf et al., 1995, 1997; Al-Sarraf, 2002). However, given the paucity of blood vessels in very immature brain it is likely that much of the amino acid detected in brain tissue of, for example neonatal rodent, arrived there via the choroid plexuses and CSF. Another interpretational difficulty is that these experiments were done before data on individual transporters were available. Thus, at best we can only compare individual or classes of amino acids shown to be transported in vivo in the developing brain with the various families of SLC transporters known to transport individual or classes of amino acids (Table 5). However, the finding (described in the papers cited above) that transport of many amino acids in developing brain is greater than in the adult strongly supports the proposition that the higher expression of many amino acid transporters in the developing brain is indeed reflected in greater transport activity.

\section{Metal Transport}

Both of the major zinc transporter families (Slc30, ZnT and Slc39, ZIP) are represented in our two datasets. The members of the two families function in opposite directions, thus maintaining cellular zinc homeostasis. ZnT proteins of Slc30 gene efflux zinc whereas ZIP proteins function to increase zinc uptake when cellular zinc is depleted (Marger et al., 2014; Tepaamorndech et al., 2014). In the context of transfer of zinc across the epithelial cells of the choroid plexus it may be that they operate in tandem. Support for this comes from the observation that SCL39A6 (LIV1) has been immunolocalised to the apical membrane of the neonatal choroid plexus epithelial cells (Chowanadisai et al., 2005).

None of the six Slc30 genes identified in this study (two high in the embryo, Slc30a2, Slc30a10, and four in the adult, Slc30a3$6,2.7-4.5$ FC) have previously been reported in choroid plexus. Of the three Slc39a genes identified (Slc39a8, 37 FC higher in embryo; Slc39a12 and Slc39a13, FC 12 and 3.9 higher in adult, respectively) none appear to have been identified previously in choroid plexus. The microarray data show that Slc30 and Slc39 genes identified in E15, but not in adult, are still expressed at the perinatal stages. Other genes of these families whose expression is lower at E15 display a rapid developmental increase in expression, to reach adult level shortly after birth. Altogether this suggests that choroidal zinc transport is substantial throughout development.

Zinc is an essential nutrient for many cellular biochemical processes (Tyszka-Czochara et al., 2014) and is essential for normal brain development and function (Sandstead, 1985). The requirement for zinc is increased during embryonic development and deficiency results in birth defects (McKenzie et al., 1975; Sandstead et al., 1975), including multiple defects in neuronal development, by mechanisms that are unclear (Chowanadisai et al., 2013a; Grabrucker et al., 2014). Slc39a12 (ZIP12) has been found to be highly expressed in brain of human and mouse adults and in development appears to be involved in early stages of neuronal differentiation and neurite outgrowth, through its role as a zinc transporter (Chowanadisai et al., 2013a,b). Zinc has specific functions in synaptic transmission. 5-15\% of the brain's zinc content is concentrated in synaptic vesicles of glutamatergic neurons. This is of importance for neuronal function in the developing and adult brain, but the identification of several genes for glutamate receptors and other transmitters, as reported earlier (Liddelow et al., 2013) suggests that the zinc transporters in choroid plexus may have a function in relation to the innervation of the choroid plexus. A more general consideration of the importance for neural function in the brain is outside the scope of this paper. Finally, zinc transporters, like other metal transporters, may transport this metal for use by the epithelial cells themselves, as discussed below.

Iron uptake into the brain occurs across both the blood-brain and blood-CSF barriers (Moos and Morgan, 2000). Transferrin, which binds iron, makes an important contribution at both interfaces, but there are some differences in the mechanisms involved. At the blood-brain barrier, transferrin receptors on the cerebral endothelial cells bind transferrin-carrying iron, which is taken up into the cells. This mechanism and subsequent 
steps in iron delivery to the brain have been described in detail (e.g., Leitner and Connor, 2012; Singh et al., 2014) and will not be considered further here. However, the uptake of both iron and transferrin is greater in the developing brain, the more so for iron itself (Morgan and Moos, 2002). The involvement of the choroid plexuses in iron transport into the brain in addition to transferrin uptake via transferrin receptors also involves the synthesis and secretion of transferrin into the CSF (Leitner and Connor, 2012). In the adult brain it has been suggested that the choroid plexuses, compared to the cerebral vasculature may play a much larger role in iron uptake than previously thought (Rouault et al., 2009). As mentioned above in relation to other transport properties, the early development of the choroid plexuses compared to brain vasculature (Johansson et al., 2008) indicates that the plexuses are likely to be even more important for iron transport in the developing brain. The likely importance of the transferrin gene, $T f$, for iron transport in both the embryonic and adult choroid plexus is emphasized by the high transcript numbers (Table 6), although much higher in the adult (183 fold). Tf expression however increases rapidly, and is only 5- and 2.3 times lower at E19 and P2 respectively than in adult. Several other iron transporters were expressed at a higher level in the embryo than in the adult: sideroflexin-1, Sfxn 1 and ferritin light chain 1-like (LOC100360087), but in terms of transcripts both were expressed at lower levels than Tf (Table 6). Slc11a1 and hephaestin were only expressed in the embryonic plexus but at low levels, so their functional contribution is doubtful. The transferrin receptor was expressed at a higher level in embryonic choroid plexus (Table 6) but this was reversed at birth. Several studies have described developmentally regulated immunohistochemical staining for several of the iron transporters in the choroid plexus (e.g., Siddappa et al., 2003; Wang et al., 2008). Moos and Morgan (1998) have provided direct evidence for the transfer of ${ }^{59} \mathrm{Fe}$ from blood into brain and CSF. The importance for iron in brain function lies in its involvement in cellular respiration and cell proliferation during development. The brain also requires iron for myelination and neurotransmission (Leitner and Connor, 2012).

Manganese $(\mathrm{Mn})$ is an essential biological element and a necessary cofactor in a number of important enzymatic reactions (Gunter et al., 2013) and is an essential micronutrient for normal brain development (Santamaria and Sulsky, 2010). Manganese transport has been demonstrated in choroid plexus freshly isolated from P2 and adult rats; uptake into plexus cells was found to be greater in $\mathrm{P} 2$ choroid plexuses. Unidirectional blood-toCSF transport of manganese was demonstrated using P2-derived in vitro reconstituted epithelium (Schmitt et al., 2011). As these authors point out it is not possible to link this transport to specific transporters but suggest the divalent metal transporters SLC11a2, SLC11a3, SLC39a8, and SCL39a14 as potential candidates. In the RNA-Seq and array screens in the present study Slc11a1 (8.9 fold) and Slc39a8 (37 fold) were expressed at higher levels in the embryonic and perinatal choroid plexus, which correlated with the higher uptake shown by Schmitt et al. (2011). In addition, transport of manganese by transferrin has been demonstrated (Gunter et al., 2013). Copper is an essential nutrient for normal growth and development of the fetus and neonate (Uriu-Adams et al., 2010). It is a co-factor for several enzymes and also a structural component with involvement in many physiological pathways in the brain; in particular it is a component of cytochrome $c$ oxidase, a member of the super-family of heme-copper-containing oxidases (Scheiber et al., 2014). In addition to divalent ion transporters thought to transport copper that were identified in the present study (e.g., Slc11a2) at least two more specific copper transporters were expressed in the choroid plexus. Ceruloplasmin was expressed at modest transcript numbers some 6.2 fold higher in the adult plexus (Table 6). The high affinity copper transporter, Slc31a1, was amongst the highest expressed transporter genes at both ages identified in this study and was 4.6 fold higher in the adult (Table 6). These data are in accordance with in situ hybridization showing the expression of Slc31a1 in choroid plexus and its rapid, choroid plexus-restricted increase from E14 to E18.5 in mice (Kuo et al., 2001). These authors suggest that the choroid plexus is a major pathway of copper supply to the developing brain.

Thus, genes for all of the main metal transporters have been identified in the choroid plexus, several of them expressed at higher levels in the embryo than in the adult, presumably reflecting the importance of their involvement in brain development. Metals are also needed for normal choroidal epithelial functions. Iron-containing cytochrome levels are high in choroid plexus as a result of high mitochondrial activity. Copper, zinc, and manganese are cofactors of several enzymatic systems, in particular superoxide dismutases (SOD) involved in regulating oxidative stress. Both $\mathrm{Mn}-\mathrm{SOD}$ and $\mathrm{Cu}-\mathrm{Zn}-\mathrm{SOD}$ are well expressed in choroid plexus throughout development (Yon et al., 2008, 2011). Thus, a primary function of metal transporters in the choroid plexus may be to supply metals required for proper functioning of the blood-CSF barrier. Of note, copper deficiency leads to a specific increase in Slc31a1 expression at the choroid plexus, a finding interpreted as a compensatory mechanism to spare the choroid plexus itself from copper deficiency (Gybina and Prohaska, 2006).

\section{Immunohistochemistry}

The protein products and their cellular distribution were demonstrated in E15 and adult choroid plexus for a selection of the Slcs identified in the gene screens, using immunohistochemistry. Three patterns of immunostaining were identified in E15 plexus epithelial cells: (i) differential immunoreactivity with regional distribution (e.g., SLC16a10), (ii) strong immunoreactivity with uniform distribution (SLC1a3), and (iii) weak immunoreactivity with uniform distribution (SLC5a5). In the adult plexus two different patterns of immunoreactivity in epithelial cells were noted: (i) strong immunoreactivity (SLC5a5) and (ii) weak or lack of immunoreactivity (SLC1a3, SLC16a10, SLC39a4). In a previous study (Liddelow et al., 2013) we illustrated immunostaining for SLC4a1 that was strong and uniformly distributed in E15 rat choroid plexus. Immunostaining for AQP1 has also been shown to have a uniform cellular distribution which was strong in E15 rat choroid plexus with characteristic localization in the apical 
TABLE 7 | Comparison of expression level (transcript numbers) and immunostaining for protein gene product.

\begin{tabular}{|c|c|c|c|c|c|}
\hline Gene ID & Protein ID & E15 transcript raw counts & E15 immunostaining & Adult transcript raw counts & Adult immunostaining \\
\hline Slc16a10 & MCT10 & 3089 & Strong, regional & 51 & Weak, uniform \\
\hline Slc38a5 & SNAT5 & 1021 & Moderate, uniform & 6 & Minimal, few patches \\
\hline Slc4a1 & $\mathrm{AE} 1^{*}$ & 7109 & Strong, uniform & 70 & Minimal-absent \\
\hline Slc11a1 & NRAMP & 130 & Moderate, uniform & 8 & Absent \\
\hline Slc1a3 & EAAT1 & 4372 & Strong, uniform & 577 & Weak, uniform \\
\hline Slc5a5 & NIS & 163 & Weak, uniform & 4916 & Strong, uniform \\
\hline Slc39a4 & ZIP4 & 58 & Weak, uniform & 38 & Apical, membrane \\
\hline Aqp1 & $\mathrm{AQP} 1^{\star *}$ & 20112 & Strong, uniform & 32149 & Very strong, uniform \\
\hline
\end{tabular}

Uniform indicates all cells were positive. Regional indicates staining confined to only some (contiguous) cells.

* from Liddelow et al. (2013), "* from Johansson et al. (2005).

membrane of all epithelial cells with weaker staining in the basolateral membrane; in the adult plexus the immunostaining was even stronger (Johansson et al., 2005). There was good correspondence between gene expression level and strength of protein immunostaining (Table 7).

\section{Limitations of Study}

There are several limitations in this study. One concerns the use of whole choroid plexus tissue. However, as discussed previously (Liddelow et al., 2013) the epithelium is the predominant cell type, representing up to $90 \%$ of the plexus tissue (Keep and Jones, 1990; Liddelow et al., 2012). The absence of transcript for Cldn5 (a brain barrier cerebral endothelial-specific claudin family member) in the current RNA-Seq dataset suggests that any possible contamination is below detectable limits (Liddelow et al., 2013). The immunohistochemical evidence in that paper and in the current study for a range of protein products of the genes identified in the choroid plexus samples showed that these proteins were largely confined to the epithelial cells of the plexus. The analysis of large RNA sequencing databases is still quite new and relies on the accuracy of the annotations for each species studied. The rat genome is well annotated and the number of unknown genes is very low, however, there is still the possibility that some transcripts were missed. The papers based on microarray studies of adult mouse choroid plexus (Marques et al., 2011 and Janssen et al., 2013) on adult human and mouse adult choroid plexus provide important additional data on gene expression in the choroid plexuses of other species. These together with that of Liddelow et al. (2012) a mouse microarray study and that of Ek et al. (2015) an RNA-Seq study in primate choroid plexus provide comprehensive datasets for interspecies comparison reviews; however, this is outside the scope of this research paper.

We did not attempt to analyze all functional groups represented in the transcriptomic dataset. For example Slc16a10 showed strikingly high expression (Table 4) exclusively in the embryo; it has been included primarily because it is a monocarboxylate transporter (MCT10) although its little investigated putative function as a thyroid hormone transporter may well prove to be more functionally important. This high expression in the embryonic choroid plexus is in striking contrast to the expression of the best-known thyroxine transporter, Slc16a2, which barely changed expression during development.

Another limitation is that, as pointed out above, expression data alone do not necessarily equate to functional activity. The immunohistochemical evidence in this paper, in Liddelow et al. (2013) and in earlier reports summarized in the Discussion shows that at least some of the mRNAs are being translated to protein. The summary of in vivo physiological transport studies for glucose, amino acids, monocarboxylates and metals in developing brain show a good correlation with the level of expression of relevant transporter genes, although because of overlap and redundancy it is generally not possible to pinpoint the specific contribution of any one gene.

\section{Conclusions}

The results from this study and two earlier ones on gene expression in embryonic and adult rat choroid plexus (Kratzer et al., 2013; Liddelow et al., 2013) as well as a study of embryonic and adult mouse choroid plexus (Liddelow et al., 2012) show that a very large number of transporter genes are expressed in the embryonic lateral ventricular choroid plexuses as early as E15 which is only a day after these plexuses appear in the rat brain (Johansson et al., 2005). In the present study $64 \%$ of all the 389 known SLC transporters, with representatives of all but 4 of the 52 SLC families, were identified. Many of these were expressed at higher or similar levels in the embryonic compared to the adult plexus. This suggests that the lateral ventricular choroid plexuses make an important contribution to supply of nutrients and micronutrients to the brain early in development. This conclusion is supported by the results of immunohistochemistry for a number of the protein products of genes expressed in the embryonic and adult choroid plexus (Figure 4), as well as data from published transport studies for glucose, monocarboxylates, amino acids and divalent metals summarized in the Discussion.

\section{Author Contributions}

All of the listed authors contributed to the conception, design, research, drafting and final approval of the work. They each agree to be accountable for all aspects of the work. 


\section{Acknowledgments}

KD, MH and NRS are supported by the National Health and Medical Research Council (Australia) - Grants No.567205 and 1049287. SL, KD, NRS, NS and J-FG-E were supported by the European Union Seventh Framework Program (FP7) Neurobid consortium - Agreement No. HEALTH-F2-2009241778, J-FG-E is supported by ANR-10-IBHU-0003 Cesame grant, SL was supported as a Neurological Fellow by the

\section{References}

Abbott, N. J., and Friedman, A. (2012). Overview and introduction: the blood-brain barrier in health and disease. Epilepsia 53(Suppl. 6), 1-6. doi: 10.1111/j.1528-1167.2012.03696.x

Abbott, N. J., Patabendige, A. A., Dolman, D. E., Yusof, S. R., and Begley, D. J. (2010). Structure and function of the blood-brain barrier. Neurobiol. Dis. 37, 13-25. doi: 10.1016/j.nbd.2009.07.030

Al-Sarraf, H. (2002). Transport of 14C-gamma-aminobutyric acid into brain, cerebrospinal fluid and choroid plexus in neonatal and adult rats. Brain Res. Dev. Brain Res. 139, 121-129. doi: 10.1016/S0165-3806(02)00537-0

Al-Sarraf, H., Preston, J. E., and Segal, M. B. (1995). The entry of acidic amino acids into brain and CSF during development, using in situ perfusion in the rat. Dev. Brain Res. 90, 151-158. doi: 10.1016/0165-3806(96)83495-X

Al-Sarraf, H., Preston, J. E., and Segal, M. B. (1997). Changes in the kinetics of the acidic amino acid brain and CSF uptake during development in the rat. Dev. Brain Res. 102, 127-134. doi: 10.1016/S0165-3806(97)00089-8

Anders, S. (2010). HTSeq 0.4.7p4. Available online at: http://www-huber.embl.de/ users/anders/HTSeq/.

Baños, G., Daniel, P. M., and Pratt, O. E. (1978). The effect of age upon the entry of some amino acids into the brain, and their incorporation into cerebral protein. Dev. Med. Child Neurol. 20, 335-346.

Baud, O., Fayol, L., Gressens, P., Pellerin, L., Magistretti, P., Evrard, P., et al. (2003). Perinatal and early postnatal changes in the expression of monocarboxylate transporters MCT1 and MCT2 in the rat forebrain. J. Comp. Neurol. 465, 445-454. doi: 10.1002/cne.10853

Bauer, H. (1998). "Glucose transporters in mammalian brain development," in Introduction to the Blood-Brain Barrier, ed W. M. Pardridge (Cambridge: Cambridge University press), P175-P187.

Benrabh, H., and Lefauconnier, J. M. (1996). Blood-endothelial cell and bloodbrain transport of L-proline, alpha-aminoisobutyric acid, and L-alanine. Neurochem. Res. 21, 1227-1235. doi: 10.1007/BF02532400

Braun, L. D., Cornford, E. M., and Oldendorf, W. H. (1980). Newborn rabbit blood-brain barrier is selectively permeable and differs substantially from the adult. J. Neurochem. 34, 147-152. doi: 10.1111/j.1471-4159.1980. tb04633.x

Brown, P. D., Davies, S. L., Speake, T., and Millar, I. D. (2004). Molecular mechanisms of cerebrospinal fluid production. Neuroscience 129, 957-970. doi: 10.1016/j.neuroscience.2004.07.003

Chowanadisai, W., Graham, D. M., Keen, C. L., Rucker, R. B., and Messerli, M. A. (2013a). Neurulation and neurite extension require the zinc transporter ZIP12 (slc39a12). Proc. Natl. Acad. Sci. U.S.A. 2110, 9903-9908. doi: $10.1073 /$ pnas. 1222142110

Chowanadisai, W., Graham, D. M., Keen, C. L., Rucker, R. B., and Messerli, M. A. (2013b). A zinc transporter gene required for development of the nervous system. Commun. Integr. Biol. 6:e26207. doi: 10.4161/cib.26207

Chowanadisai, W., Kelleher, S. L., and Lönnerdal, B. (2005). Zinc deficiency is associated with increased brain zinc import and LIV-1 expression and decrease ZnT-1 expression in neonatal rats. J. Nutr. 135, 1002-1007.

Cornford, E. M., Braun, L. D., and Oldendorf, W. H. (1982). Developmental modulations of blood-brain barrier permeability as an indicator of changing nutritional requirements in the brain. Pediatr. Res. 16, 324-328. doi: 10.1203/00006450-198204000-00017
American-Australian Association and as an NHMRC CJ Martin Fellow.

\section{Supplementary Material}

The Supplementary Material for this article can be found online at: http://journal.frontiersin.org/article/10.3389/fnins. 2015.00123/abstract

Cornford, E. M., and Cornford, M. E. (1986). Nutrient transport and the bloodbrain barrier in developing animals. Fed. Proc. 45, 2065-2072.

Cremer, J. E. (1982). Substrate utilization and brain development. J. Cereb. Blood Flow Metab. 2, 394-407. doi: 10.1038/jcbfm.1982.45

Damkier, H. H., Brown, P. D., and Praetorius, J. (2013). Cerebrospinal fluid secretion by the choroid plexus. Physiol. Rev. 93, 1847-1892. doi: 10.1152/physrev.00004.2013

Damkier, H. H., Nielsen, S., and Praetorius, J. (2007). Molecular expression of SLC4-derived Na+-dependent anion transporters in selected human tissues. Am. J. Physiol. Regul. Integr. Comp. Physiol. 293, R2136-R2146. doi: 10.1152/ajpregu.00356.2007

Daneman, R., Zhou, L., Agalliu, D., Cahoy, J. D., Kaushal, A., and Barres, B. A. (2010). The mouse blood-brain barrier transcriptome: a new resource for understanding the development and function of brain endothelial cells. PLoS ONE. 5:e13741. doi: 10.1371/journal.pone.0013741

Davson, H., and Segal, M. B. (1996). Physiology of the CSF and Blood-Brain Barriers. Boca Raton, FL: CRC Press.

Ek, C. J., Nathanielsz, P., Li, C., and Mallard, C. (2015). Transciptomal changes and functional annotation of the developing non human primate choroid plexus. Front. Neurosci. 9:82. doi: 10.3389/fnins.2015.00082

Gentleman, R. C., Carey, V. J., Bates, D. M., Bolstad, B., Dettling, M., Dudoit, S., et al. (2004). Bioconductor: open software development for computational biology and bioinformatics. Genome Biol. 5, R80. doi: 10.1186/gb-2004-5-10r80

Grabrucker, S., Jannetti, L., Eckert, M., Gaub, S., Chhabra, R., Pfaender, S., et al. (2014). Zinc deficiency dysregulates the synaptic ProSAP/Shank scaffold and might contribute to autism spectrum disorders. Brain 137(Pt 1), 137-152. doi: 10.1093/brain/awt303

Gray, S., Feinberg, M. W., Hull, S., Kuo, C. T., Watanabe, M., Sen-Banerjee, S., et al. (2002). The Krüppel-like factor KLF15 regulates the insulin-sensitive glucose transporter GLUT4. J. Biol. Chem. 277, 34322-34328. doi: 10.1074/jbc.M2013 04200

Gunter, T. E., Gerstner, B., Gunter, K. K., Malecki, J., Gelein, R., Valentine, W. M., et al. (2013). Manganese transport via the transferrin mechanism. Neurotoxicology 34, 118-127. doi: 10.1016/j.neuro.2012.10.018

Gybina, A. A., and Prohaska, J. R. (2006). Variable response of selected cuproproteins in rat choroid plexus and cerebellum following perinatal copper deficiency. Genes Nutr. 1, 51-59. doi: 10.1007/BF02829936

Hediger, M. A. (2013). The ABCs of membrane transporters in health and disease (SLC series). Mol. Aspects Med. 34, 95-752. doi: 10.1016/j.mam.2012.12.009

Hubbard, T. J., Aken, B. L., Ayling, S., Ballester, B., Beal, K., Bragin, E., et al. (2009). Ensembl 2009. Nucleic Acids Res. 37, D690-D697. doi: 10.1093/nar/gkn828

Janssen, S. F., van der Spek, S. J., Ten Brink, J. B., Essing, A. H., Gorgels, T. G., van der Spek, P. J., et al. (2013). Gene expression and functional annotation of the human and mouse choroid plexus epithelium. PLOS ONE 8:e83345. doi: 10.1371/journal.pone.0083345

Johansson, P. A., Dziegielewska, K. M., Ek, C. J., Habgood, M. D., Liddelow, S. A., Potter, A. M., et al. (2006). Blood-CSF barrier function in the rat embryo. Eur. J. Neurosci. 24, 65-76.

Johansson, P. A., Dziegielewska, K. M., Ek, C. J., Habgood, M. D., Møllgård, K., Potter, A., et al. (2005). Aquaporin-1 in the choroid plexuses of developing mammalian brain. Cell Tissue Res. 322, 353-364. doi: 10.1007/s00441-005$1120-\mathrm{x}$ 
Johansson, P. A., Dziegielewska, K. M., Liddelow, S. A., and Saunders, N. R. (2008). The blood-CSF barrier explained: when development is not immaturity. Bioessays 30, 237-248. doi: 10.1002/bies.20718

Keep, R. F., and Jones, H. C. (1990). A morphometric study on the development of the lateral ventricular choroid plexus, choroid plexus capillaries and ventricular ependyma in the rat. Dev. Brain Res. 56, 47-53. doi: 10.1016/01653806(90)90163-S

Keep, R. F., and Smith, D. E. (2011). Choroid plexus transport: gene deletion studies. Fluids Barriers CNS 8:26. doi: 10.1186/2045-8118-8-26

Koehler-Stec, E. M., Simpson, I. A., Vannucci, S. J., Landschulz, K. T., and Landschulz, W. H. (1998). Monocarboxylate transporter expression in mouse brain. Am. J. Physiol. 275(3 Pt 1), E516-E524.

Kohle, S. J., and Vannucci, R. C. (1977). Glycogen metabolism in fetal and postnatal rat brain: influence of birth. J. Neurochem. 28, 441-443. doi: 10.1111/j.14714159.1977.tb07768.x

Kratzer, I., Liddelow, S. A., Saunders, N. R., Strazielle, N., and Ghersi-Egea, J. F. (2013). Developmental changes in the transcriptome of the rat choroid plexus in relation to neuroprotection. Fluids Barriers CNS. 10:25. doi: 10.1186/2045-81 18-10-25

Kuo, Y. M., Zhou, B., Cosco, D., and Gitschier, J. (2001). The copper transporter CTR1 provides an essential function in mammalian embryonic development. Proc. Natl. Acad. Sci. U.S.A. 98, 6836-6841. doi: 10.1073/pnas.111057298

Langmead, B., Trapnell, C., Pop, M., and Salzberg, S. L. (2009). Ultrafast and memory efficient alignment of short DNA sequences to the human genome. Genome Biol. 10:R25. doi: 10.1186/gb-2009-10-3-r25

Lefauconnier, J.-M., and Trouvé, R. (1983). Developmental changes in the pattern of amino acid transport at the blood-brain barrier in rats. Brain Res. 283, 175-182. doi: 10.1016/0165-3806(83)90095-0

Leino, R. L., Gerhart, D. Z., and Drewes, L. R. (1999). Monocarboxylate transporter (MCT1) abundance in brains of suckling and adult rats: a quantitative electron microscopic immunogold study. Brain Res. Dev. Brain Res. 113, 47-54. doi: 10.1016/S0165-3806(98)00188-6

Leitner, D. F., and Connor, J. R. (2012). Functional roles of transferrin in the brain. Biochim. Biophys. Acta 1820, 393-402. doi: 10.1016/j.bbagen.2011.10.016

Liddelow, S. A., Dziegielewska, K. M., Ek, C. J., Habgood, M. D., Bauer, H., Bauer, H.-C., et al. (2013). Mechanisms that determine the internal environment of the developing brain: a transcriptomic, functional and ultrastructural approach. PLoS ONE 8:e65629. doi: 10.1371/journal.pone.0065629

Liddelow, S. A., Temple, S., Møllgård, K., Gehwold, R., Wagner, A., Bauer, H., et al. (2012). Molecular characterisation of transport mechanisms at the developing mouse blood-CSF interface: a transcriptome approach. PloS ONE 7:e33554. doi: 10.1371/journal.pone.0033554

Marger, L., Schubert, C. R., and Bertrand, D. (2014). Zinc: an underappreciated modulatory actor of brain function. Biochem. Pharmacol. 91, 426-435. doi: 10.1016/j.bcp.2014.08.002

Marques, F., Sousa, J. C., Coppola, G., Gao, F., Puga, R., Brentani, H., et al. (2011). Transcriptome signature of the adult mouse choroid plexus. Fluids Barriers CNS 8:10. doi: 10.1186/2045-8118-8-10

McKenzie, J. M., Fosmire, G. J., and Sandstead, H. H. (1975). Zinc deficiency during the latter third of pregnancy: effects on fetal rat brain, liver, and placenta. J. Nutr. 105, 1466-1475.

Moos, T., and Morgan, E. H. (1998). Evidence for low molecular weight, nontransferrin-bound iron in rat brain and cerebrospinal fluid. J. Neurosci. Res. 54, 486-494.

Moos, T., and Morgan, E. H. (2000). Transferrin and transferrin receptor function in brain barrier systems. Cell. Mol. Neurobiol. 20, 77-95. doi: 10.1023/A:1006948027674

Morgan, E. H., and Moos, T. (2002). Mechanism and developmental changes in iron transport across the blood-brain barrier. Dev. Neurosci. 24, 106-113. doi: $10.1159 / 000065699$

Nehlig, A. (1997). Cerebral energy metabolism, glucose transport and blood flow: changes with maturation and adaptation to hypoglycaemia. Diabetes Metab. 23, $18-29$.

Netsky, M. G., and Shuangshoti, S. (1975). The Choroid Plexus in Health and Disease. Bristol: Wright.

Porterfield, S. P., and Hendrick, C. E. (1992). Tissue iodothyronine levels in fetuses of control and hypothyroid rats at 13 and 16 days gestation. Endocrinology 131, 195-200. doi: 10.1210/en.131.1.195
Rivas, M., and Naranjo, J. R. (2007). Thyroid hormones, learning and memory. Genes Brain Behav. 6 Suppl. 1, 40-44. doi: 10.1111/j.1601-183X.2007.00321.x

Robinson, M. D., McCarthy, D. J., and Smyth, D. K. (2010). edgeR: a Bioconductor package for differential expression analysis of digital gene expression data. Bioinformatics 26, 139-140. doi: 10.1093/bioinformatics/btp616

Rouault, T. A., Zhang, D-L., and Jeong, S. Y. (2009). Brain iron homeostasis, the choroid plexus, and localization of iron transport proteins. Metab. Brain Dis. 24, 673-684. doi: 10.1007/s11011-009-9169-y

Sandstead, H. H. (1985). WO Atwater memorial lecture. Zinc: essentiality for brain development and function. Nutr. Rev. 43, 129-137.

Sandstead, H. H., Fosmire, G. J., McKenzie, J. M., and Halas, E. S. (1975). Zinc deficiency and brain development in the rat. Fed. Proc. 34, 86-88. doi: 10.1007/978-1-4684-2631-1_19

Santamaria, A. B., and Sulsky, S. (2010). Risk assessment of an essential element: manganese. J. Toxicol. Environ. Health A 73, 128-55. doi: $10.1080 / 15287390903337118$

Saunders, N. R., Daneman, R., Dziegielewska, K. M., and Liddelow, S. A. (2013). Transporters of the blood-brain and blood-CSF interfaces in development and in the adult. Mol. Aspects Med. 34, 742-752. doi: 10.1016/j.mam.2012.11.006

Saunders, N. R., Liddelow, S. A., and Dziegielewska, K. M. (2012). Barrier mechanisms in the developing brain. Front. Pharmacol. 3:46. doi: 10.3389/fphar.2012.00046

Schachenmayr, W. Z. (1967). On the development of ependyma and plexus choriodeus of the rat. Zellforsch. Mikrosk. Anat. 77, 25-63.

Scheiber, I. F., Mercer, J. F., and Dringen, R. (2014). Metabolism and functions of copper in brain. Prog. Neurobiol. 116, 33-57. doi: 10.1016/j.pneurobio.2014.01.002

Schmitt, C., Strazielle, N., Richaud, P., Bouron, A., and Ghersi-Egea, J.-F. (2011). Active transport at the blood-CSF barrier contributes to manganese influx into the brain. J. Neurochem. 117, 747-756 doi: 10.1111/j.1471-4159.2011.07246.x

Segal, M. B. (2001). Transport of nutrients across the choroid plexus. Microsc. Res. Tech. 52, 38-48. doi: 10.1002/1097-0029(20010101)52:1\&lt;38::AIDJEMT6\&gt;3.0.CO;2-J

Sershen, H., and Lajtha, A. (1976). Capillary transport of amino acids in the developing brain. Exp. Neurol. 53, 465-474. doi: 10.1016/0014-4886(76) 90086-8

Siddappa, A. J., Rao, R. B., Wobken, J. D., Casperson, K., Leibold, E. A., Connor, J. R., et al. (2003). Iron deficiency alters iron regulatory protein and iron transport protein expression in the perinatal rat brain. Pediatr. Res. 53, 800-807. doi: 10.1203/01.PDR.0000058922.67035.D5

Singh, N., Haldar, S., Tripathi, A. K., Horback, K., Wong, J., Sharma, D., et al. (2014). Brain iron homeostasis: from molecular mechanisms to clinical significance and therapeutic opportunities. Antioxid. Redox Signal. 20, 1324-1363. doi: 10.1089/ars.2012.4931

Skeaff, S. A. (2011). Iodine deficiency in pregnancy: the effect on neurodevelopment in the child. Nutrients 3, 265-273. doi: 10.3390/nu3020265

Tepaamorndech, S., Kirschke, C. P., and Huang, L. (2014). Linking cellular zinc status to body weight and fat mass: mapping quantitative trait loci in $\mathrm{ZnT7}$ knockout mice. Mamm Genome. 25, 335-353. doi: 10.1007/s00335-014-9512-4

Tyszka-Czochara, M., Grzywacz, A., Gdula-Argasiñska, J., Librowski, T., Wiliñski, B., and Opoka, W. (2014). The role of zinc in the pathogenesis and treatment of central nervous system (CNS) diseases. Implications of zinc homeostasis for proper CNS function. Acta Pol. Pharm. 71, 369-377.

Uriu-Adams, J. Y., Scherr, R. E., Lanoue, L., and Keen, C. L. (2010). Influence of copper on early development: prenatal and postnatal considerations. Biofactors 36, 136-152. doi: 10.1002/biof.85

Vannucci, R. C., and Vannucci, S. J. (2000). Glucose metabolism in the developing brain. Semin. Perinatol. 24, 107-115. doi: 10.1053/sp.2000.6361

Vannucci, S. J. (1994). Developmental expression of GLUT1 and GLUT3 glucose transporters in rat brain. J. Neurochem. 62, 240-246.

Vannucci, S. J., Rutherford, T., Wilkie, M. B., Simpson, I. A., and Lauder, J. M. (2000). Prenatal expression of the GLUT4 glucose transporter in the mouse. Dev. Neurosci. 22, 274-282. doi: 10.1159/000017451

Vannucci, S. J., and Simpson, I. A. (2003). Developmental switch in brain nutrient transporter expression in the rat. Am. J. Physiol. Endocrinol. Metab. 285, E1127-E1134. doi: 10.1152/ajpendo.00187.2003

Wang, X., Miller, D. S., and Zheng, W. (2008). Intracellular localization and subsequent redistribution of metal transporters in a rat choroid plexus 
model following exposure to manganese or iron. Toxicol. Appl. Pharmacol. 230:167-174. doi: 10.1016/j.taap.2008.02.024

Wright, E. M. (2013). Glucose transport families SLC5 and SLC50. Mol. Aspects Med. 34, 183-196. doi: 10.1016/j.mam.2012.11.002

Yon, J. M., Baek, I. J., Lee, B. J., Yun, Y. W., and Nam, S. Y. (2011). Dynamic expression of manganese superoxide dismutase during mouse embryonic organogenesis. Int. J. Dev. Biol. 55, 327-334. doi: 10.1387/ijdb.103270jy

Yon, J. M., Baek, I. J., Lee, S. R., Kim, M. R., Lee, B. J., Yun, Y. W., et al. (2008). Immunohistochemical identification and quantitative analysis of cytoplasmic $\mathrm{Cu} / \mathrm{Zn}$ superoxide dismutase in mouse organogenesis. J. Vet. Sci. 9, 233-240. doi: $10.4142 /$ jvs.2008.9.3.233
Conflict of Interest Statement: The authors declare that the research was conducted in the absence of any commercial or financial relationships that could be construed as a potential conflict of interest.

Copyright $\odot 2015$ Saunders, Dziegielewska, Møllgård, Habgood, Wakefield, Lindsay, Stratzielle, Ghersi-Egea and Liddelow. This is an open-access article distributed under the terms of the Creative Commons Attribution License (CC BY). The use, distribution or reproduction in other forums is permitted, provided the original author(s) or licensor are credited and that the original publication in this journal is cited, in accordance with accepted academic practice. No use, distribution or reproduction is permitted which does not comply with these terms. 